\title{
State-of-the-art technology in variable compression ratio mechanism for spark ignition engine
}

\author{
ASHISH J CHAUDHARI, VINAYAK KULKARNI and NIRANJAN SAHOO* \\ Centre for Energy, Indian Institute of Technology Guwahati, Guwahati 781 039, India \\ e-mail: shock@iitg.ernet.in; shock@iitg.ac.in
}

MS received 31 May 2017; revised 20 March 2018; accepted 16 July 2018; published online 3 December 2018

\begin{abstract}
Present investigations deal with development of a novel variable compression ratio (VCR) mechanism and its implementation in a small and relatively large size single-cylinder engines. Operation of this mechanism is found to be smooth and effective in the running condition of the engine as well. This mechanism, when incorporated in the small size spark ignition HONDA engine, portrayed improvement in engine performance with increment in compression ratio (CR) for petrol and kerosene. Their respective optimum CRs 5.02 (petrol) and 5.27 (kerosene) are higher than the base value 4.8. In case of large size KIRLOSKAR engine, the present VCR mechanism is found to be useful while operating with liquefied petroleum gas (LPG), where measurements showed that combustion duration is lower with LPG for CR 9.79 as compared with base value 9.0. The present experiments clearly demonstrate the usefulness of VCR mechanism in improving engine performance for a given fuel and broadening the range of alternative fuels burnt in the engine. Ease of fabrication, simplicity in installation, accessibility in troubleshooting and smooth run-time alterations are the advantages with the current novel mechanism.
\end{abstract}

Keywords. Variable compression ratio; spark ignition engine; ball screw assembly; engine head modification; clearance volume.

\section{Introduction}

The internal combustion (IC) engines are used across a range of vehicles from passenger cars to heavy transport vehicles and for power farm equipment. In view of such extensive use of the IC engines, many governments and allied organizations are insisting for innovations to adapt fuel-economy standards. Variable compression ratio (VCR) is one of the promising technologies considered to enhance the performance of the engine and thereby achieve fuel economy. Provision of the VCR attachment is essential to vary the compression ratio (CR), especially for spark ignition (SI) engines, where "knocking phenomenon" limits the performance. Besides, these Otto-cycle-based IC engines, used in most of the applications, have fixed CR. This constraint limits the engine performance with uncontrolled usage of a given fuel and narrows down the type of fuels to be burnt in the engine. VCR technology broadens the application envelope of the engine by improving its performance for a given fuel and facilitates flexibility of use of various fuels. Thus, ability to vary the CR reduces the dependence on a particular fuel. Moreover, it improves the engine performance for the same maximum possible

*For correspondence cycle temperature and load conditions with use of a particular fuel.

Over the past few years, various companies have developed several prototypes related to VCR engine, although those products are not yet realized in large scale. However, development of some mechanisms for VCR is the outcome of all those efforts. In the year 1924, the VCR concept was first put forth by Matson [1] using a compensating connecting rod for varying the $\mathrm{CR}$, and later by Kratzer [2] in 1942 though development of a VCR engine. Then, in 1956, Mansfield [3] worked on a piston-enabled mechanism for VCR in IC engine. Among all the developments so far, the notable ones are based on modification in cylinder head [4] and crankshaft side [5, 6]. A "Pressure Reactive Piston (PRP)" technology with modification of the piston geometry has also been developed [7]. Here, the CR varies with the increase or decrease of cylinder pressure.

Implementation of VCR mechanism for performance analysis of an engine has also been a topic of research in the open literature. Caris and Nelson [8] conducted experiments on a series of eight-cylinder engines to understand the effect of CR on volumetric efficiency, mean effective pressure and indicated thermal efficiency using gasoline. The best performance of the engine has been reported at an intermediate CR. Abdel and Osman [9] studied the effect of varying the $\mathrm{CR}$ on the engine performance with different 
ethanol-gasoline fuel blends. It has been noticed that, for each fuel blend, there is an optimum CR that gives the maximum indicated power. Ozcan and Jehad [10] developed a computer simulation model of a variable-strokelength LPG (liquefied petroleum gas)-fuelled, singlecylinder, four-stroke, SI engine. Results were analysed at various engine speeds and corresponding power and torque. Yuh and Tohru [11] conducted research to observe the effect of higher CRs in two-stroke engines. The results showed improvement in fuel consumption for each unit rise in $\mathrm{CR}$ in the range of 6.6-13.6. It was concluded that the maximum $\mathrm{CR}$ is limited due to knock and increase in thermal load. Some researchers have also focused on emission analysis for a VCR engine [12, 13]. Investigations with two-stroke and four-stroke engines have also shown performance improvement of the engine in the presence of VCR [14]. Research works based on design and developments of such technologies in IC engines have been reported in the open literature [15-17].

With reference to these techniques, present investigations have received the motivation to design a simple VCR mechanism for an SI engine. The proposed mechanism has a secondary piston in the secondary cylinder, which reciprocates inside the combustion chamber (figures 1, 2). Novelty of this mechanism lies in the fact that the spark plug is installed in the secondary piston, which reduces space requirement for exclusive mounting of the secondary piston. This mechanism is expected to accommodate wide range of CRs even during the running condition of the engine. The major advantage of such mechanism would be that the engine can operate at its best performance for all possible variants of petrol available in the province and also it can run on other SI engine fuels. With this mechanism, the engine can as well be tuned for a given fuel or blend of fuels to deliver optimized performance. In view of these listed efforts related to VCR engine, objective of the present studies is centred on exploring the possibility of effective testing of multiple fuels in an SI engine equipped with newly designed VCR mechanism. This objective internally demands alteration in CRs with change in fuel (i.e., octane rating). These studies would ultimately be useful to suggest the effective CR for different octane rating fuels to test in the same engine. Therefore, a newly designed and developed VCR mechanism is incorporated in two commercial multi-fuel engines for the present investigations. Performance of those engines has been assessed for different fuels at different CRs since it is a well acknowledged fact that an IC engine can operate at the highest possible CR for attaining the highest overall efficiency. However, the gain in efficiency beyond a certain CR can be expected to be marginal due to other influencing factors such as heat loss and friction [18]. Thus, present experiments also propose to examine the upper limit of CR for the combination of fuel and SI engine beyond which there is fall in efficiency [19]. The details of the experimental setups, design and fabrication of VCR mechanism and results obtained from the experiments are given in following sections.

\section{Experimental facility}

The proposed VCR mechanism belongs to the group in which $\mathrm{CR}$ is altered by changing the clearance volume of the engine. For the present studies, this mechanism is attached to a small size engine and a large size engine. Detailed specifications of those engines are given in table 1. Process of design and installation of the present VCR mechanism is discussed in this section for small engines. The same process of design and installation procedure is followed in a bigger scale of this VCR mechanism for large size engines.

\subsection{VCR mechanism for small size engines}

A schematic of this mechanism, for the small size HONDA (Model GK100) engine, along with other components is as shown in figure 1. This mechanism is necessarily an assembly of a secondary cylinder, secondary piston, piston rings, ball screw and ball screw nut. Design and geometrical details of this mechanism are given in figure 2. Here, an indigenously designed cylinder replaces the original head of the engine to accommodate the VCR mechanism. During the operation of this VCR mechanism, a small secondary piston, fixed on the main head with the help of a ball screw, reciprocates in the secondary cylinder. This secondary piston is equipped with piston rings for sealing the space during operation. Such isolation is essential for smooth operation of the engine. These piston rings are designed by considering the dynamic forces applied on the rings due to cylinder pressure in combustion chamber [20]. Using these first principles and considering various forces, the dimensions of secondary piston, its rings and cylinder are decided with the help of Eqs. (1)-(5). More details are available in references [21-23]:

$$
\begin{aligned}
& \text { secondary piston diameter } d_{p}=\sqrt{\frac{F V_{d} N}{\pi B P n}}+d_{\text {spark }}, \\
& \text { secondary piston thickness } t_{w}=\frac{F}{\pi(0.85) d_{p} \sigma_{\text {allow }}}, \\
& \text { secondary cylinder wall thickness } t=\frac{D P_{\max }}{2 \sigma_{c}} \\
& \text { piston ring radial thickness } t_{r}=\sqrt{\frac{4 P_{\text {rad }} r^{2}}{\sigma_{\text {allow }}}}
\end{aligned}
$$

piston ring free length

$$
l_{g}=2 \pi\left\{\left[\frac{E t_{r} r^{\prime}}{E t_{r}-\left(2 \sigma_{\text {allow }} r^{\prime}\right)}\right]-r^{\prime}\right\} \text {. }
$$



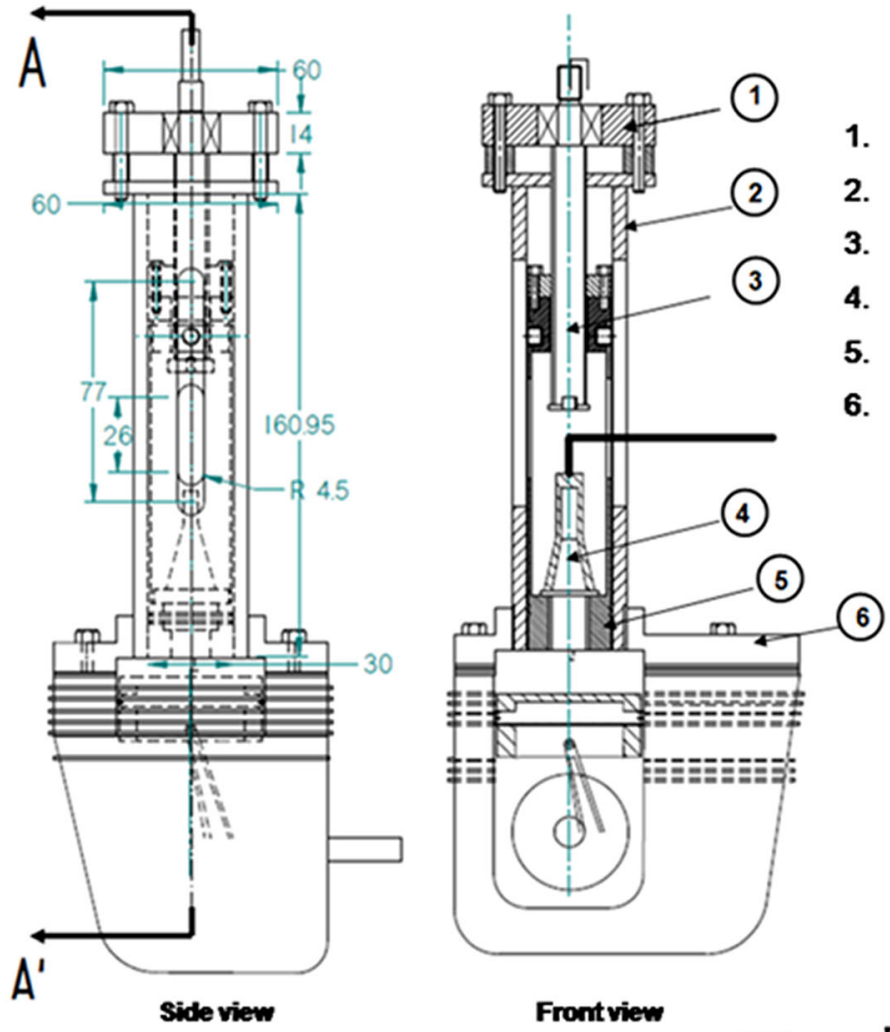

(a)

Frontview

1. VCR Mechanism head

2. Secondary Cylinder

3. Ballscrew and nut assembly

4. Sparkplug and plug cap

5. Secondary piston

6. Modified Engine head

All dimensions are in 'mm'.

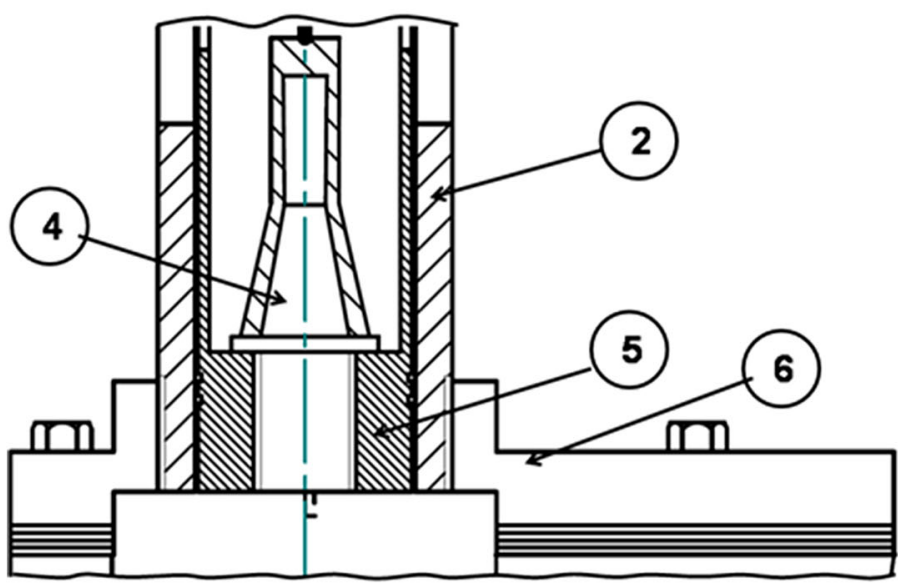

(b)

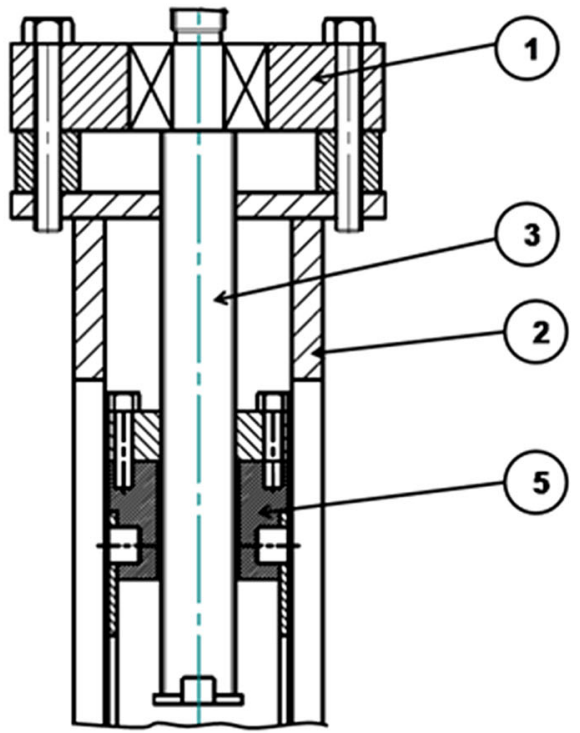

(c)

Figure 1. Details of VCR attachment assembled with SI engine: (a) schematic of VCR mechanism, (b) enlarged view of VCR mechanism towards engine cylinder block and (c) enlarged view of the VCR mechanism showing the secondary piston and ball screw motion.

The ball screw (figure 2b) has threads of constant pitch and it converts the rotary motion of the screw to linear motion of nut, which slides over the grooves. The lock nut arrests the ball screw over bearings. The ball screw nut (figure 2c) having small balls glides over the screw threads, giving linear motion to the nut. The screw stopper limits the maximum travel of the nut over the ball screw. The ball screw and nut are designed based on the engine specification and subsequent calculations. Here, the driving force on the ball screw is the maximum cylinder pressure inside the engine that acts directly over the circular cross-sectional area of secondary piston. This ball screw design is chosen 


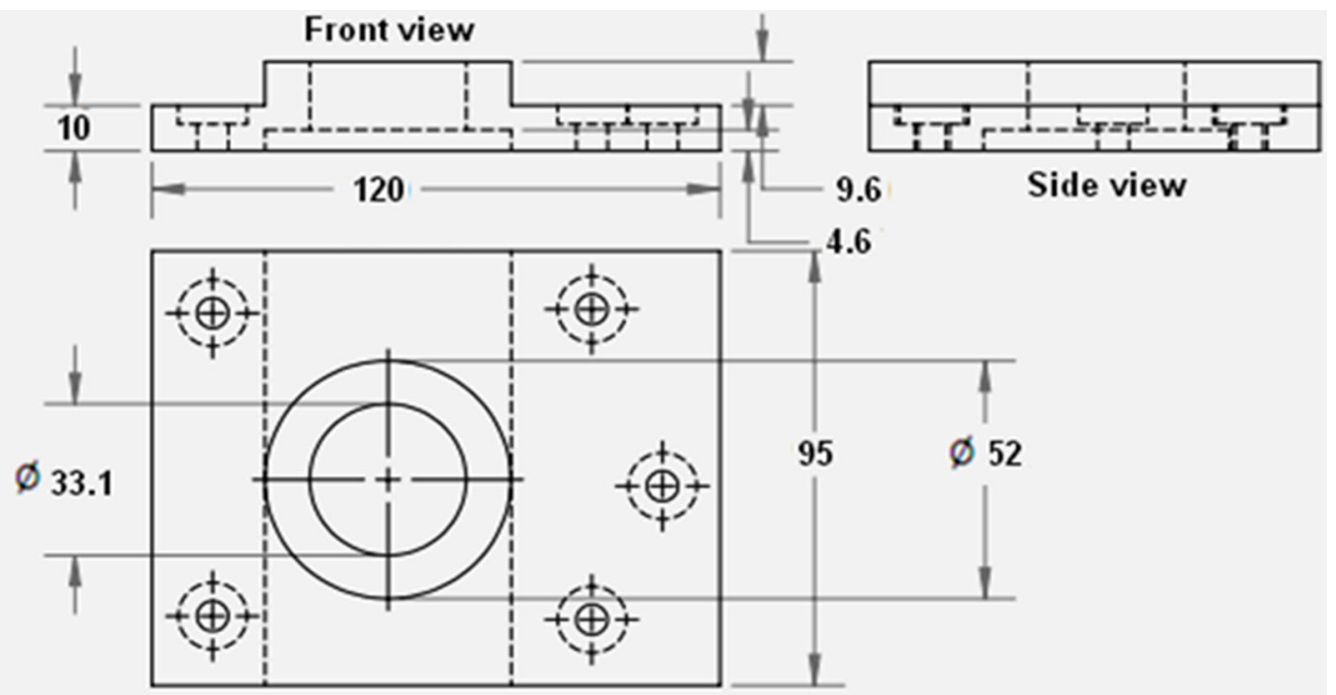

Top view

(a)

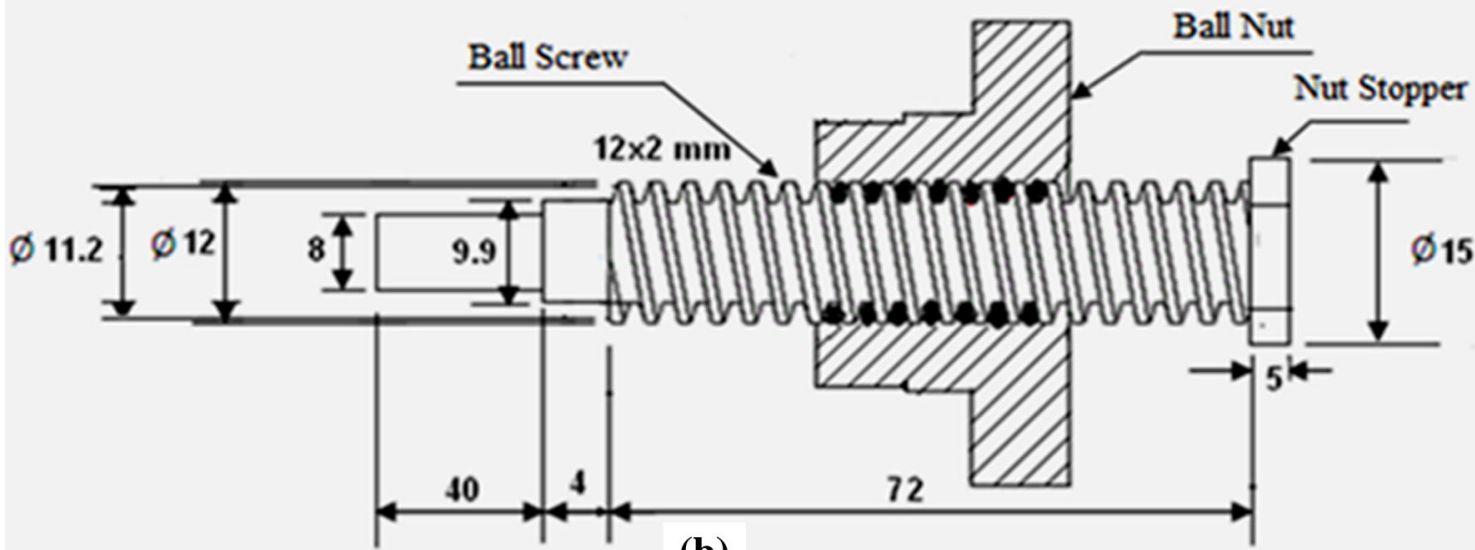

(b)
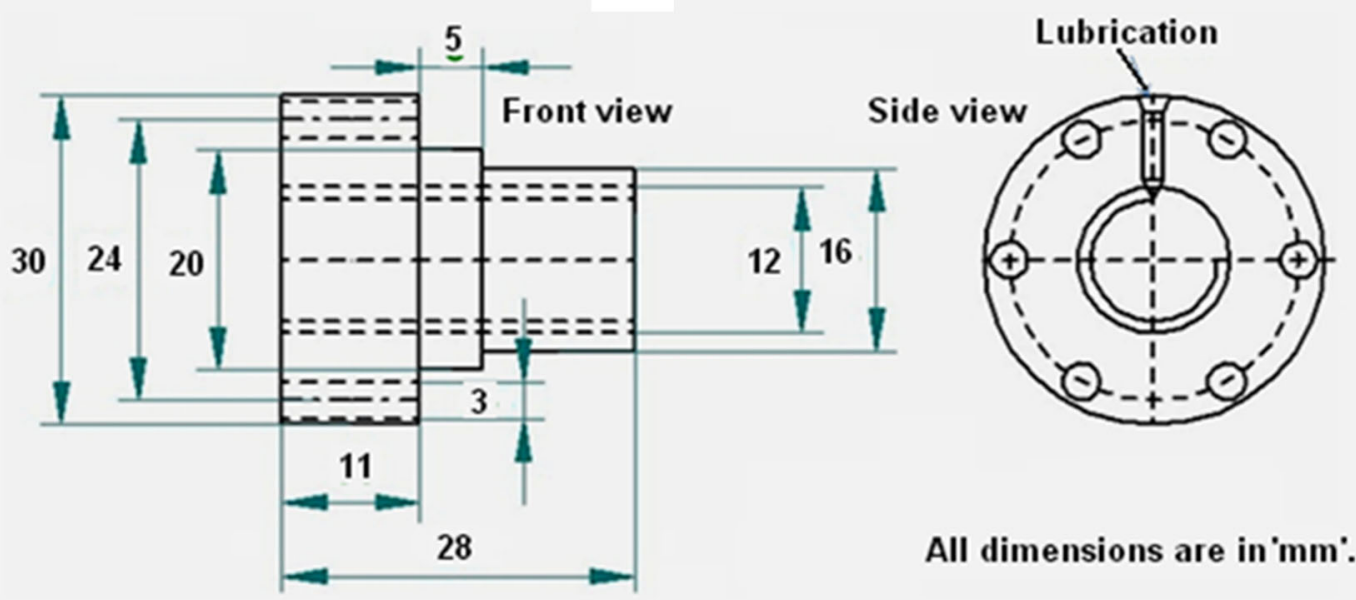

All dimensions are in ' $\mathrm{mm}$ '.

(c)

Figure 2. Design details of VCR mechanism assembled with SI engine: (a) modified cylinder head (no. 6 of figure 1), (b) ball screw (no. 4 of figure 1) and (c) ball nut (no. 5 of figure 1). 
Table 1. Specifications of spark ignition engine.

\begin{tabular}{|c|c|c|}
\hline Engine & Small size & Large size \\
\hline Make & HONDA GK100 & $\begin{array}{c}\text { Apex make engine } \\
\text { set-up }\end{array}$ \\
\hline Type & $\begin{array}{c}\text { Side valve, } 4 \text {-stroke, air- } \\
\text { cooled, horizontal } \\
\text { shaft, single cylinder }\end{array}$ & $\begin{array}{l}\text { Single-cylinder, } \\
\text { 4-stroke, water- } \\
\text { cooled spark } \\
\text { ignition }\end{array}$ \\
\hline $\begin{array}{l}\text { Displacement } \\
\text { (swept } \\
\text { volume })\end{array}$ & $97.7 \mathrm{~cm}^{3}$ & $661 \mathrm{~cm}^{3}$ \\
\hline Bore $\times$ stroke & $(52 \times 46) \mathrm{mm}$ & $(87.5 \times 110) \mathrm{mm}$ \\
\hline $\begin{array}{l}\text { Compression } \\
\text { ratio }\end{array}$ & $4.8: 1$ & $\begin{array}{c}\text { 6-10 (tilting block } \\
\text { VCR) }\end{array}$ \\
\hline $\begin{array}{l}\text { Rated horse } \\
\text { power }\end{array}$ & 1.3 kW@4200 rpm & 4.5 kW@1800 rpm \\
\hline $\begin{array}{l}\text { Ignition } \\
\text { system/timing }\end{array}$ & $\mathrm{TCI} / 20^{\circ} \mathrm{bTDC}$ & Variable \\
\hline
\end{tabular}

from the manufacturer's catalogue so as to suit its static and dynamic loading. Equations (6) and (7) are considered to fix the dimensions of ball screw:

$$
\begin{aligned}
& \text { ball screw static capacity } C_{o}=F \times S . F, \\
& \text { ball screw dynamic capacity } \\
& \quad C_{a o}=\left(X F_{r}+Y F_{a}\right)\left(\frac{60 N_{b} L_{h}}{10^{6}}\right)^{0.33} .
\end{aligned}
$$

During the operation of the mechanism, this nut ultimately helps the linear motion of the secondary piston. Subsequently, this linear motion of the secondary piston is accompanied with a spark plug fixed inside it. Thus, clearance volume gets altered by the operation of the VCR mechanism. This mechanism is designed with an objective to arrive at an optimum CR in order to achieve the maximum efficiency of the SI engine for a given fuel. The specifications of novel VCR mechanism, attached to small size engine, are listed in table 2 . This technique can as well be incorporated in all the SI engine fuels like petrol, LPG, $\mathrm{CNG}$, biogas, etc., and also for all diesel engine fuels like diesel, biofuels, etc. In case of a diesel engine, a fuel injector can be fitted in the position of the spark plug. Characteristic features of this mechanism are ease of installation and accessibility in trouble-shooting. Along with this, it is indeed possible to change the CR in running condition of the engine with the present novel mechanism.

\subsection{Implementation of VCR in a small size engine}

A single-cylinder SI engine (Make: HONDA; Model GK 100 ) is used in one set of experiments of present studies. It is necessarily a single-cylinder, air-cooled engine having

\begin{tabular}{|c|c|c|c|c|}
\hline \multirow[b]{2}{*}{$\begin{array}{l}\text { Sr. } \\
\text { no. }\end{array}$} & \multirow[b]{2}{*}{$\begin{array}{l}\text { Name of } \\
\text { component }\end{array}$} & \multirow[b]{2}{*}{ Specification } & \multicolumn{2}{|c|}{$\begin{array}{l}\text { Major dimensions } \\
(\mathrm{mm})\end{array}$} \\
\hline & & & $\begin{array}{l}\text { HONDA } \\
\text { engine }\end{array}$ & $\begin{array}{l}\text { APEX } \\
\text { engine }\end{array}$ \\
\hline \multirow[t]{4}{*}{01} & \multirow{4}{*}{$\begin{array}{r}\text { Secondary } \\
\text { cylinder }\end{array}$} & Outside diameter & 38.10 & 38.10 \\
\hline & & $\begin{array}{c}\text { Thickness of } \\
\text { cylinder }\end{array}$ & 3.5 & 3.5 \\
\hline & & $\begin{array}{l}\text { Height of } \\
\text { cylinder }\end{array}$ & 150.63 & 236.92 \\
\hline & & Flange diameter & 61.10 & 61.30 \\
\hline \multirow[t]{8}{*}{02} & \multirow{8}{*}{$\begin{array}{l}\text { Secondary } \\
\text { piston }\end{array}$} & Outside diameter & 31.10 & 31.10 \\
\hline & & Crown thickness & 24.20 & 15.20 \\
\hline & & $\begin{array}{l}\text { Piston groove } \\
\text { radial depth }\end{array}$ & 2.02 & 2.02 \\
\hline & & $\begin{array}{r}\text { Piston groove } \\
\text { axial depth }\end{array}$ & 2.02 & 1.45 \\
\hline & & $\begin{array}{c}\text { Piston groove } \\
\text { gap }\end{array}$ & 2.02 & 4.33 \\
\hline & & $\begin{array}{c}\text { No. of piston } \\
\text { rings }\end{array}$ & 2 & 3 \\
\hline & & $\begin{array}{l}\text { Total height of } \\
\text { piston }\end{array}$ & 150.46 & 179.80 \\
\hline & & $\begin{array}{c}\text { Wall thickness } \\
\text { of piston }\end{array}$ & 3.5 & 3.5 \\
\hline \multirow[t]{3}{*}{03} & \multirow[t]{3}{*}{ Ball screw } & Length of screw & 134 & 134 \\
\hline & & $\begin{array}{l}\text { Mean diameter } \\
\text { of screw }\end{array}$ & M12 & M12 \\
\hline & & Pitch & 2 & 2 \\
\hline \multirow[t]{2}{*}{04} & \multirow[t]{2}{*}{ Ball nut } & $\begin{array}{c}\text { Maximum } \\
\text { diameter of } \\
\text { nut }\end{array}$ & 31 & 30 \\
\hline & & $\begin{array}{c}\text { Total height of } \\
\text { nut }\end{array}$ & 28 & 28 \\
\hline \multirow[t]{2}{*}{05} & \multirow[t]{2}{*}{ Ball nut holder } & Total length & 60.03 & 60.40 \\
\hline & & $\begin{array}{c}\text { Maximum outer } \\
\text { diameter }\end{array}$ & 31 & 31 \\
\hline \multirow[t]{4}{*}{06} & \multirow[t]{4}{*}{$\begin{array}{l}\text { Secondary } \\
\text { cylinder head }\end{array}$} & $\begin{array}{c}\text { Diameter of } \\
\text { head }\end{array}$ & 61.10 & 61.30 \\
\hline & & $\begin{array}{c}\text { Thickness of } \\
\text { head }\end{array}$ & 11.20 & 14.20 \\
\hline & & No. of bolts & 6 & 6 \\
\hline & & $\begin{array}{c}\text { Mean diameter } \\
\text { of bolt }\end{array}$ & 4 & 6 \\
\hline
\end{tabular}
rated power of $1.3 \mathrm{~kW}$ at $4200 \mathrm{rpm}$. This engine is
Table 2. Specifications of the novel VCR mechanism.

equipped with a transistor coil ignition system for supply of current to the spark plug. As per the engine specifications, it is capable of running on petrol and kerosene fuels at fixed $\mathrm{CR}$ of 4.8. Carburetion and ignition timings are also same for both the fuels as per design specifications of the engine (table 1). The properties of fuels (table 3) used in present experiments are obtained from literatures [24]. During current explorations, original head of the HONDA engine is replaced with an L-type head in order to accommodate the new VCR mechanism. Clearance volume of the engine after this modification, for flush mounting of the secondary 
Table 3. Properties of test fuels used in the experiments [24].

\begin{tabular}{lccc}
\hline Property & Kerosene & Petrol & LPG \\
\hline Chemical composition & $\mathrm{C}_{12} \mathrm{H}_{26}$ & $\mathrm{C}_{8} \mathrm{H}_{18}$ & $\mathrm{C}_{3} \mathrm{H}_{8}+\mathrm{C}_{4} \mathrm{H}_{10}$ \\
Auto-ignition & 295 & 280 & $410-580$ \\
$\quad$ temperature $\left({ }^{\circ} \mathrm{C}\right)$ & & & \\
Octane number & $70-85$ & $84-95$ & 112 \\
Density at $15^{\circ} \mathrm{C}\left(\mathrm{kg} / \mathrm{m}^{3}\right)$ & $780-850$ & $730-760$ & 1.44 \\
$(A / F)_{s t}$ ratio by weight & 14.12 & 14.7 & 15.67 \\
Lower heating value $(\mathrm{kJ} /$ & 45636 & 43770 & 46400 \\
$\quad \mathrm{~kg})$ & & & \\
\hline
\end{tabular}

piston or the spark plug, is noted to be $25.52 \mathrm{~cm}^{3}$. Further change in the clearance volume due to movement of secondary piston is governed by the amount of rotation given to the ball screw. Present measurements showed that one anticlockwise rotation of the ball screw moves the secondary piston by $2 \mathrm{~mm}$ inside the clearance space. This concept is clearly demonstrated in figure $3 \mathrm{a}$. Resultant CR of the engine for corresponding movement of the secondary piston is evaluated using Eq. (8). Thus, currently proposed VCR mechanism has the capability to change CR in analogue manner. Nevertheless, figure $3 b$ gives the quantification of percentage change in clearance volume and CR for specific values of secondary piston displacements for small size engines.

$$
\mathrm{CR}=\frac{\left(V_{c, a c t}-V_{c, a u x}\right)+V_{d}}{\left(V_{c, a c t}-V_{c, a u x}\right)} ; \quad \Delta V_{c}=\frac{\left(V_{c, a c t}-V_{c, a u x}\right)}{V_{c, a c t}} .
$$

\subsection{Experimental test rig}

A schematic diagram of this HONDA engine test rig is shown in figure 4. The novel VCR mechanism attached with the engine is the major component of the experimental set-up. Various measurement systems are integrated with this engine to assess its performance. These systems include (i) air and fuel consumption measurement, (ii) Prony brake dynamometer and (iii) engine speed measurement system. Here, the engine intake port is connected to a square box of side length $360 \mathrm{~mm}$ so as to act as reservoir of air for the present set-up. This air box is equipped with an orifice meter of diameter $20 \mathrm{~mm}$ for measurement of air flow rate using a U-tube manometer. In this experimental set-up, fuel tank is connected to the engine through a tube for fuel flow measurement. A rope brake dynamometer having maximum torque with capacity of $10 \mathrm{~N}-\mathrm{m}$ is employed to measure the torque. This dynamometer is connected to the engine through a universal coupling for applying the desired brake load. Here, magnitude of load applied can be measured using two spring balances attached to the brake drum with wire rope. The brake load is thus the algebraic difference of forces associated with the two spring balances. A digital panel tachometer (Enercon Make, India) with proxy-methyl photo-reflective sensor is used for measurement of speed. This device has measurement range of up to $9999 \mathrm{rpm}$ with a sampling time of $1 \mathrm{~s}$. A photo-reflective tape is mounted on the drum face for speed measurement. During the measurement, the tachometer is always kept $150 \mathrm{~mm}$ away from the shaft. Detailed experimentation is performed on this set-up by varying the CR from its original value for petrol and kerosene till the maximum possible value at which misfire of the engine has been noticed.

The novel VCR mechanism is also designed for a large size engine (Make: KIRLOSKAR, India) of $4.5 \mathrm{~kW}$ running at $1800 \mathrm{rpm}$ with its standard specifications (table 1). This engine can run on two fuels, viz., petrol and LPG. The inbuilt tilting-block-based VCR mechanism is already placed with this engine so as to vary the CR discretely from 6 to 10 . However, present experiments are carried out with the settings of tilting block to provide the base CR as 9 . Further changes in $\mathrm{CR}$ are obtained using the presently proposed VCR mechanism. Design calculations of this mechanism are also performed in a similar manner as discussed in section 2.1. All the design details and geometrical parameters of this mechanism are given in table 2, while figure 5 shows the incorporation of this mechanism in the engine head. The engine operation with this mechanism raises the $\mathrm{CR}$ (above 9) in the same way as explained in section 2.2 and it is shown in figure 3a. Variation of CR due to operation of mechanism or movement of secondary piston is as given in figure $3 \mathrm{~b}$. Figure 6 shows a schematic diagram of the specially designed experimental set-up for this large size SI engine. Here, the engine is coupled with an eddy current dynamometer (SAJ Make, Model AG10) for loading; cooling of the engine is accomplished by circulating water through the jackets of the engine block and cylinder head. In petrol mode, fuel injection time, fuel injection angle and ignition angle can be programmed using an electronic controlling unit (ECU) at each operating point based on RPM and throttle position. Same controlling facilities are also available for LPG injection. Moreover, LPG supply to the engine is obtained through a diaphragm type gas meter followed by a diaphragm pump. This sophisticated test rig is also facilitated with different measurements like air temperature, coolant temperature and throttle position. There is also provision of measurement for combustion pressure and crank angle (CA). A standalone panel box is provided in this test rig, which accommodates an air box, two fuel tanks, a manometer, a fuelmeasuring unit, transmitters for air and fuel flow measurements, a process indicator and hardware interface. Rotameters are also provided for cooling water and calorimeter water flow rate measurements. In this experimental set-up, experiments are performed with petrol and LPG fuels (table 3 ). 


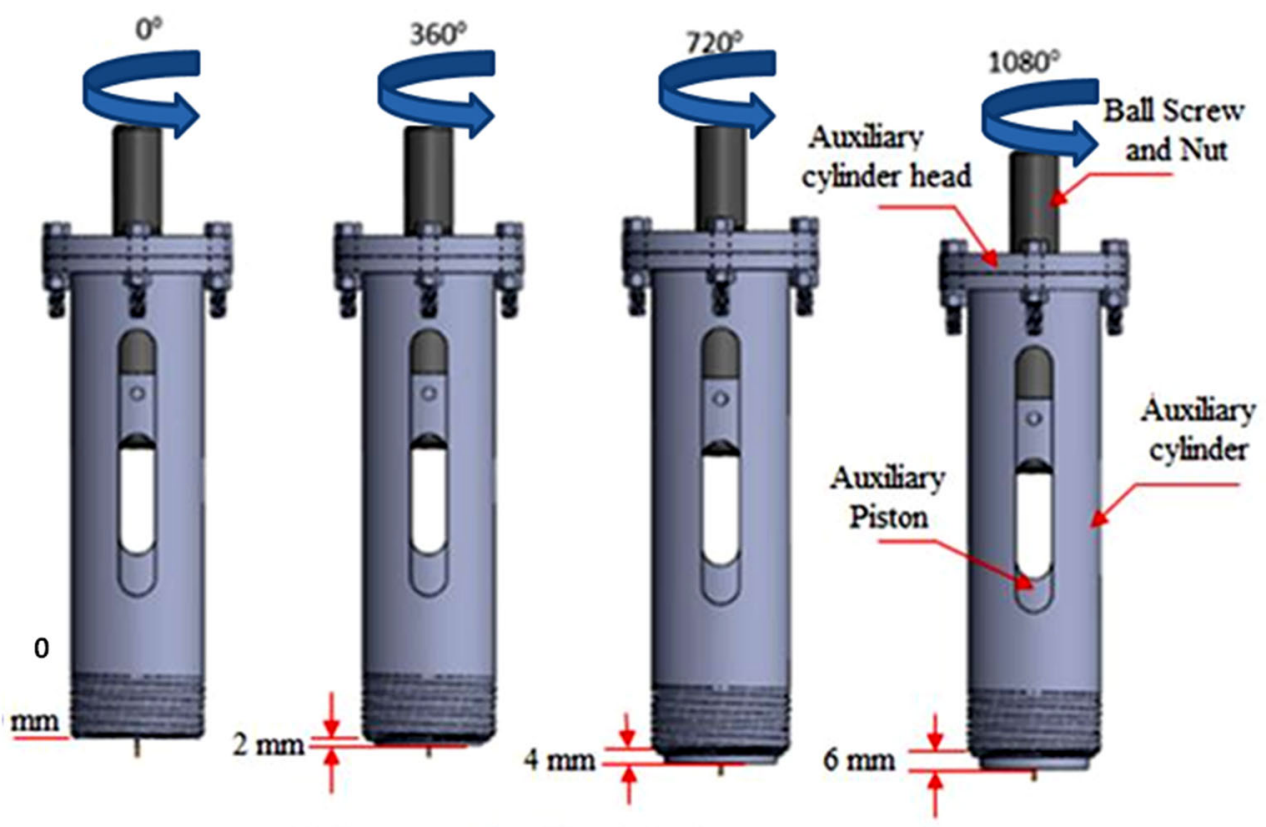

Displacement of auxiliary piston in $\mathrm{mm}$

(a)

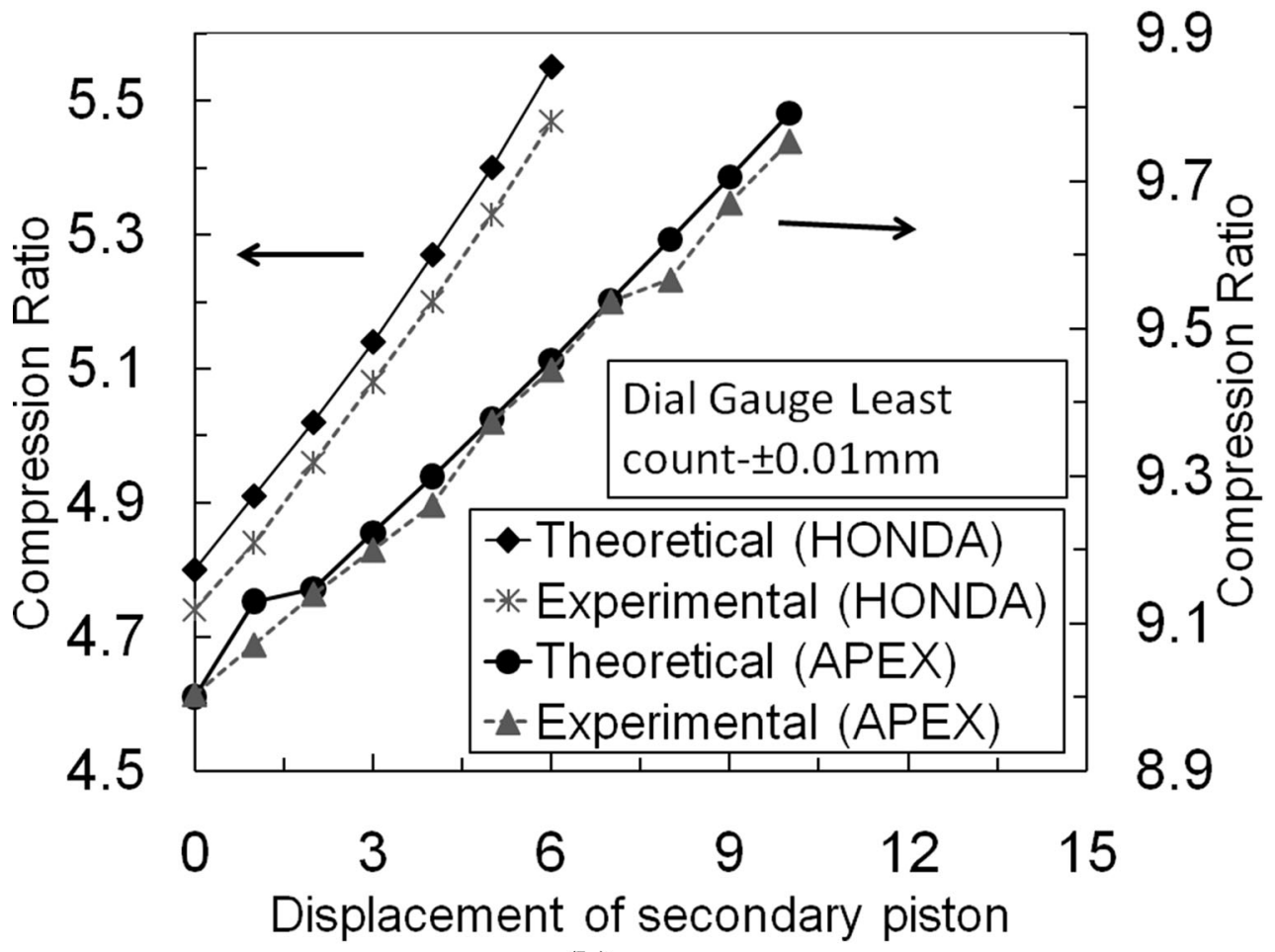

(b)

Figure 3. Operating principle of VCR mechanism: (a) displacement of secondary piston with rotation of ball screw and (b) variation of compression ratio and clearance volume with displacement of secondary piston.

\section{Results and discussion}

\subsection{Investigations with small size engine}

The performance of the HONDA engine is evaluated with petrol and kerosene fuels as per the guidelines of "Bureau of Indian Standard IS1000; Part-IV" [25]. These experiments are performed in the test rig shown in figure 4. Parameters, viz. brake power, brake-specific fuel consumption (BSFC) and brake thermal efficiency (BTE), are considered for the proposed evaluation where experiments are performed at different CRs using the present VCR 


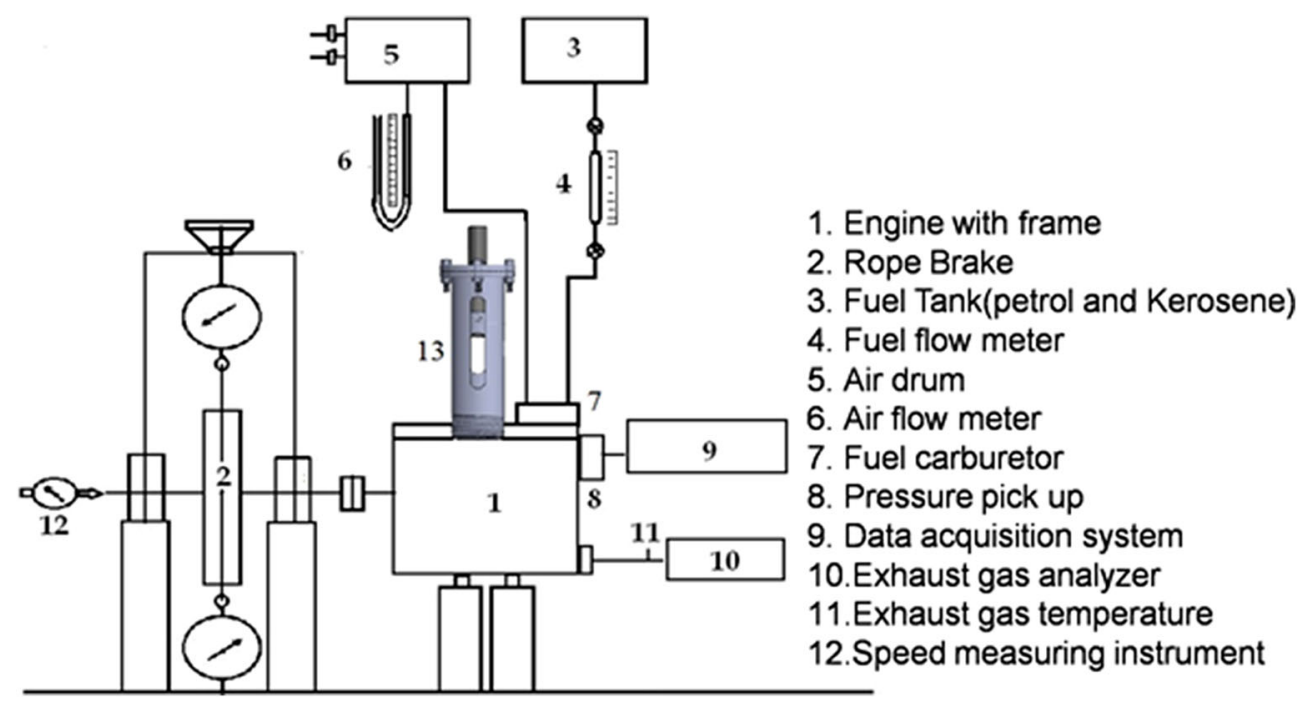

Figure 4. Schematic diagram of experimental set-up of small size engine.

mechanism for $52 \%$ wide open throttle position. Choice of this throttle position is based on the fact that on-road vehicles run between $30 \%$ and $60 \%$ throttle position for best performance and most economic fuel consumption [26]. The details of the experimental matrix are given in table 4. During present investigations, brake power is evaluated from the torque obtained from rope brake dynamometer and the rotational speed given by the tachometer (Eq. (9)):

$$
B P=2 \pi N(W-S)(R+r) .
$$

$B S F C$ is obtained using Eq. (10), which accounts for the measured value of fuel flow rate:

$$
B S F C=\frac{m_{f}}{B P} .
$$

Finally, Eq. (11) is used to calculate the BTE of the engine for different loads with the knowledge of heating value of the fuel [27]:

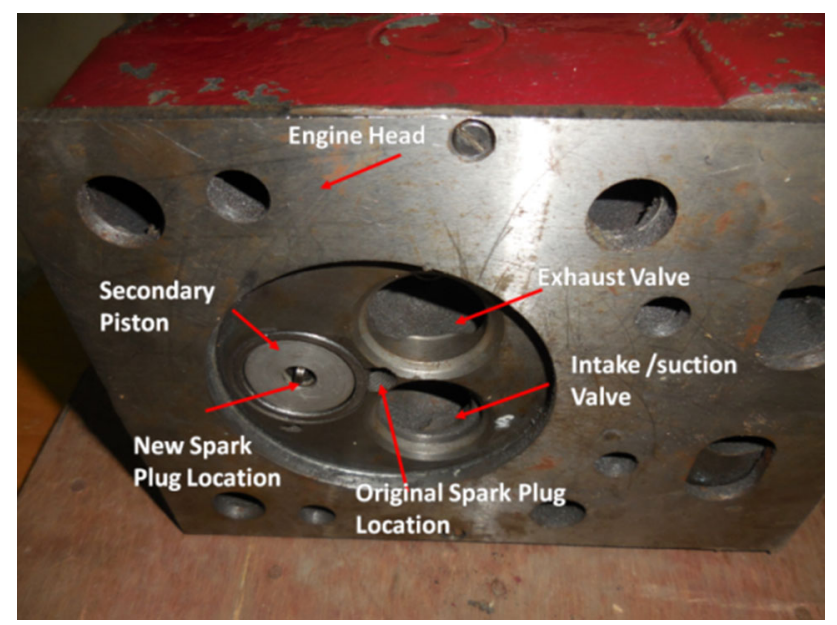

Figure 5. Pictorial view of modified head, mounting novel VCR mechanism in the large size engine.

$$
B T E=\frac{B P}{\left(m_{f} \times L H V\right)} .
$$

The presently designed VCR mechanism has been tested for different CRs above CR 4.8. In these experiments, fuel being used is petrol having research octane number 91 (RON-91) and kerosene with octane rating of 75 (RON-75) [28]. These experiments are performed with same settings as mentioned earlier and all the necessary measurements are carried out. These experiments are terminated at the knock limited speed of engine, which is achieved by applying maximum possible load. Outcomes of these measurements are plotted for petrol and kerosene in figures 7 and 8, respectively. Referring to figure $7 \mathrm{a}$, it can be seen that, for a given CR and fuel, engine torque is found to decrease with increase in speed, which is in line with the argument from literature [29]. Maximum torque recorded for petrol as fuel with CR 4.8 is $1.58 \mathrm{~N}-\mathrm{m}$ at speed $1953 \mathrm{rpm}$, whereas the minimum torque obtained is $0.28 \mathrm{~N}-\mathrm{m}$ at $2191 \mathrm{rpm}$. The same trend has been noted for kerosene as shown in figure $7 \mathrm{~b}$. The major reason for this decrement of engine torque is the reduction in load as well as time for the combustion process. It is expected that reduction in load on the engine, and hence increased speed, demands faster burning of the fuel. However, incomplete combustion due to limitation on flame speed does not release necessary chemical energy, which in turn reduces the engine torque output. The brake power also varies with the speed in the same way as that of the torque with increase in speed for both the fuels (figure 8). This observation is consistent with the fact that brake power is directly dependent on the torque and speed; hence, with increase in speed, proportionate decrease of torque is expected for corresponding reduction in power. The variation in torque and power is fuel dependent but the trend has been found to be the same for petrol and kerosene. The 


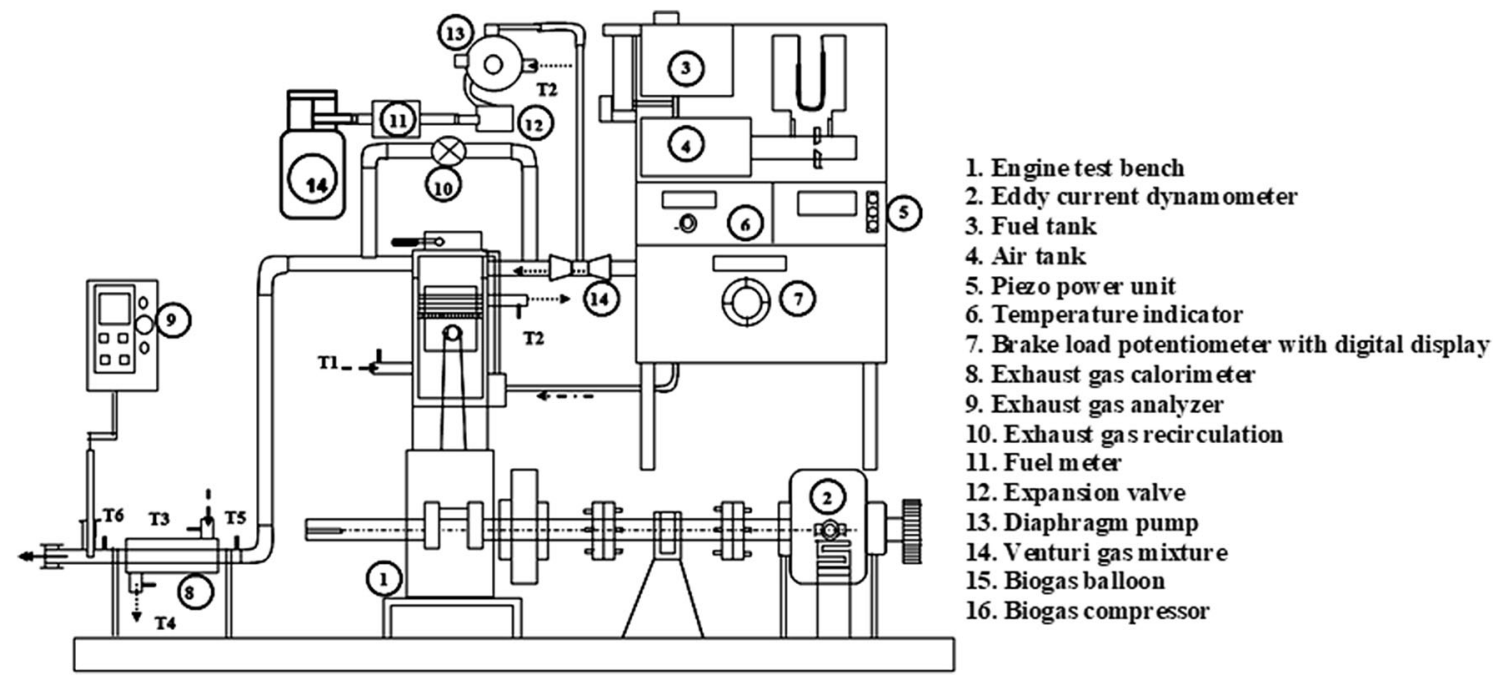

Figure 6. Schematic diagram of experimental set-up of large size engine.

Table 4. Experimental matrix.

\begin{tabular}{|c|c|c|c|c|c|c|c|c|}
\hline \multirow{3}{*}{$\frac{\text { Engine set-up }}{\text { HONDA engine }}$} & \multirow{3}{*}{$\begin{array}{c}\text { Throttle position }(\%) \\
52\end{array}$} & \multirow{3}{*}{$\begin{array}{c}\text { Fuel } \\
\text { Petrol }\end{array}$} & \multicolumn{6}{|c|}{ Compression ratio } \\
\hline & & & \multicolumn{2}{|l|}{ Original engine head } & \multicolumn{4}{|c|}{ Modified engine head } \\
\hline & & & 4.8 & 4.8 & 4.9 & 5.02 & 5.27 & 5.4 \\
\hline & 52 & Kerosene & 4.8 & 4.8 & 4.9 & 5.27 & 5. & \\
\hline \multirow[t]{2}{*}{ Apex make large engine } & 90 & Petrol & 9 & & & 9.79 & & \\
\hline & 90 & LPG & 9 & & & 9.79 & & \\
\hline
\end{tabular}

maximum power for CR 4.8 is $323 \mathrm{~W}$ at $1953 \mathrm{rpm}$ while the minimum power is $64 \mathrm{~W}$ at $2191 \mathrm{rpm}$ as seen for petrol (figure $8 \mathrm{a}$ ). In the same line and as seen from figure $8 \mathrm{~b}$, the maximum power recorded for kerosene, at the same $C R$, is
$310 \mathrm{~W}$ at $2072 \mathrm{rpm}$ while the lowest is found to be $26 \mathrm{~W}$ at $2155 \mathrm{rpm}$. The reason for lower power with kerosene is associated with its higher density and lower calorific value as compared with petrol. Effect of CR on torque and power

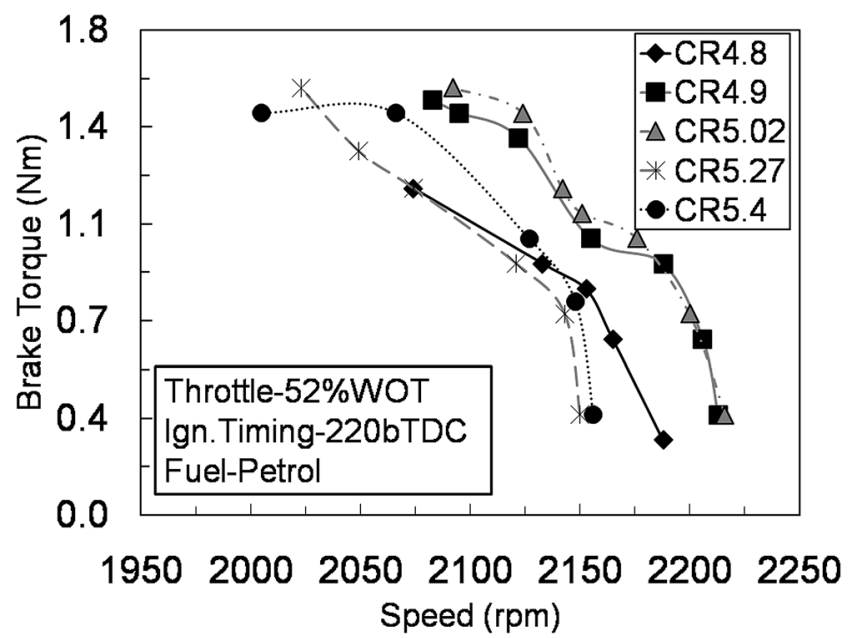

(a)

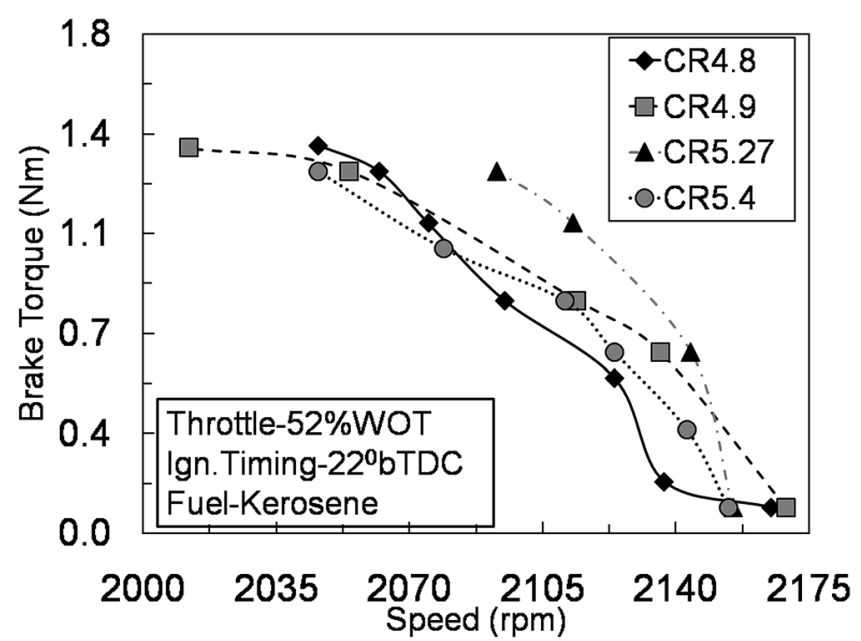

(b)

Figure 7. Variation of brake torque with modified head and VCR mechanism for (a) petrol and (b) kerosene. 


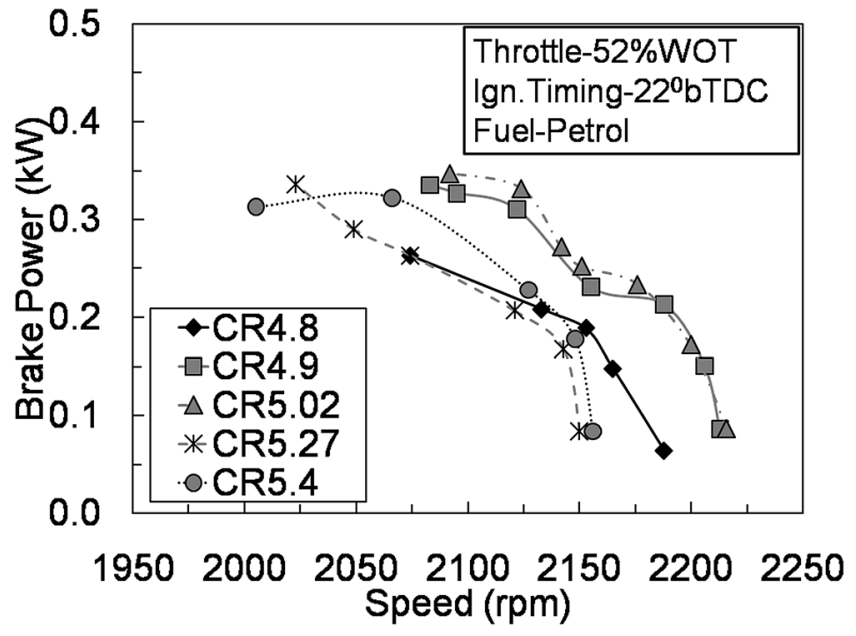

(a)

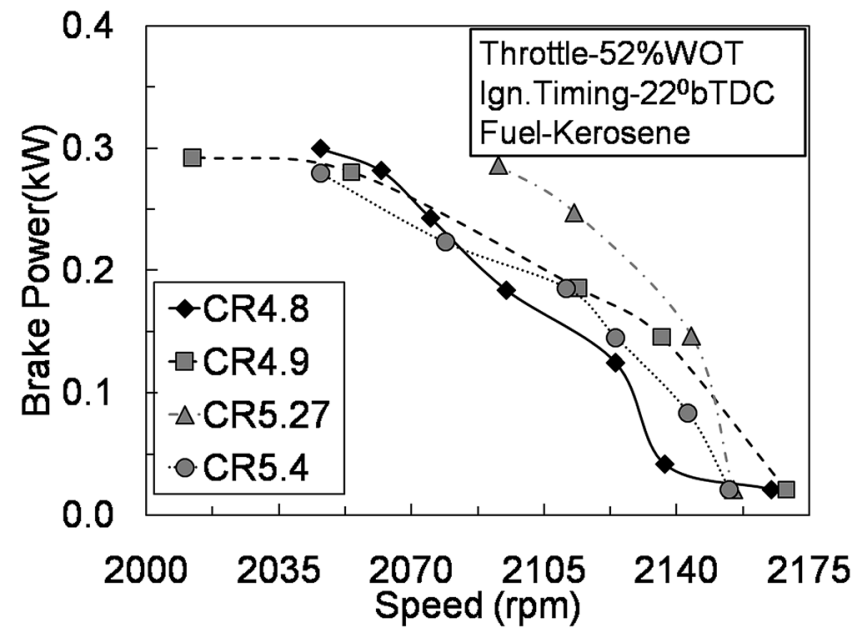

(b)

Figure 8. Variation of brake power with modified head and VCR mechanism for (a) petrol and (b) kerosene.

of engine can be further examined in the same plots (figures 7,8$)$. Here, for a given speed, torque increases initially with increase in CR and then decreases. The critical CR is 5.02 for the engine speed of $2092 \mathrm{rpm}$ in case of petrol. This observation hints for the presence of an optimum CR producing maximum torque at that speed. The maximum torque at CR 5.02 for petrol is $18 \%$ higher than the torque at default CR of 4.8 (figure 7a). It may be worth noting that the increase in CR increases friction of the engine, particularly between the piston ring and cylinder wall of engine. Hence, there is a point at which further rise in CR would not be profitable. The optimum CR is 5.27 for kerosene fuel as evident from figure $7 \mathrm{~b}$. This observation of higher value of optimum CR for kerosene is consistent with the octane rating and heating values of petrol and kerosene. With the present VCR mechanism, brake power is initially found to increase with $\mathrm{CR}$ and then it decreases.

The brake power with kerosene as fuel is found to be maximum at the $\mathrm{CR}$ of 5.27 and the percentage increment of $36 \%$ has been recorded over CR 4.8 at speed $2095 \mathrm{rpm}$ (figure $8 \mathrm{~b}$ ). The major reason for this rise in brake power (with increase in CR) is the increase in maximum cylinder pressure and in turn provides higher brake mean effective pressure (BMEP). Thus, increased BMEP for a given swept volume enhances the efficiency of the engine. This justification is in good agreement with observation of literaturereported findings [30]. Moreover, the decrement in power is observed for both fuels at any CR above the optimum CR value. At the fixed CR for a given fuel, the BTE is found to decrease with increase in speed for petrol (figure 9a) as well as for kerosene (figure 9b). At higher engine speeds, more friction losses are expected, which can account for decrement in BTE and increase in BSFC. This observation is in line with the literature findings $[31,32]$. For petrol at $\mathrm{CR}$ 4.8, the maximum $\mathrm{BTE}$ is recorded as $8.3 \%$ at
$1953 \mathrm{rpm}$ and at the same speed, minimum BSFC of $0.275 \mathrm{~kg} / \mathrm{kW}$-h is logged (figure 10a). Similarly, for kerosene fuel at the same CR, the maximum BTE is measured as $9 \%$ at $2072 \mathrm{rpm}$ and at the same speed, minimum BSFC of $0.254 \mathrm{~kg} / \mathrm{kW}-\mathrm{h}$ is noted (figure $10 \mathrm{~b}$ ).

While considering the CR effect, BTE of the engine, initially, shows increment with $\mathrm{CR}$ till optimum $\mathrm{CR}$ for both the fuels. Maximum BTE for petrol is noted at CR of 5.02 and it is $19 \%$ higher that the BTE of original CR of 4.8 as seen in figure 9a. This is because of the fact that the increased $\mathrm{CR}$ reduces the clearance volume and therefore increases the density of cylinder gases during burning. In turn, pressure and temperature increase, thereby reducing the total combustion duration and ignition lag [9]. Hence, the earlier observed optimum CR for petrol retains its place from the analysis of efficiency as well. For kerosene also, the optimum CR from the perspective of efficiency is 5.27 from figure $9 \mathrm{~b}$. In this case, the maximum efficiency is noted to be $7.1 \%$, which is about $37 \%$ higher than the efficiency corresponding to normal CR of 4.8. Moreover, for both the fuels, further increase in CR decreases the BTE. BSFC is plotted for both the fuels in figure 10. The variation of BSFC with speed is the same in either case and follows the same trend as for any given $\mathrm{CR}$ with increase in speed. Albeit, BSFC for a particular speed decreases with increase in $\mathrm{CR}$ for petrol till $\mathrm{CR}$ equals 5.02. At this $\mathrm{CR}$, $\mathrm{BSFC}$ of petrol is found to be $17 \%$ lower than that of $\mathrm{CR}$ 4.8 (figure 10a). However, onward increase in CR, above this optimum value, tends to increase the BSFC substantially. Similarly, for kerosene (figure 10b), there is $37 \%$ decrement in BSFC when the engine runs at optimum CR 5.27 with corresponding value as that of CR 4.8. These inferences are in alignment with the observations drawn from the efficiency plot. Thus, the present investigations with HONDA engine revel that the engine at its default CR 


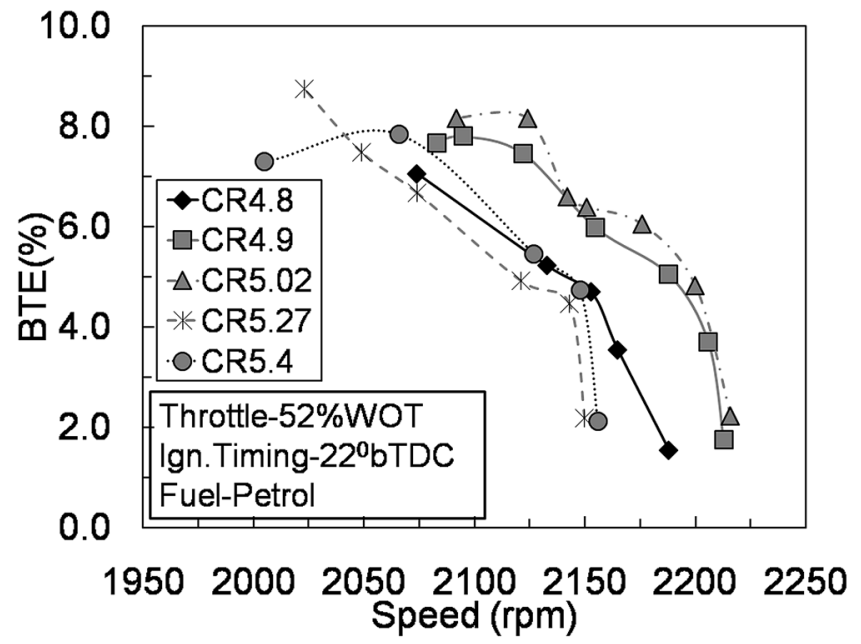

(a)

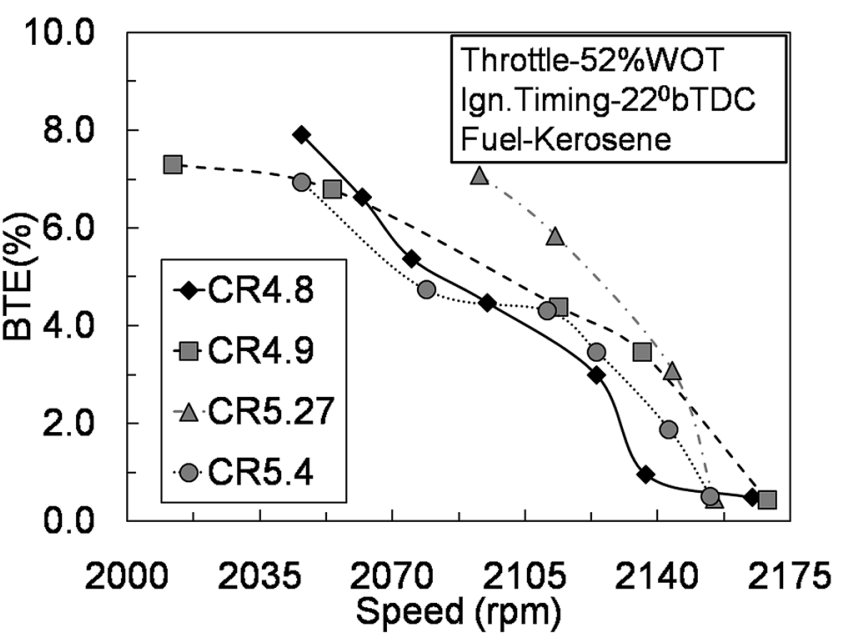

(b)

Figure 9. Variation of BTE with modified head and VCR mechanism for (a) petrol and (b) kerosene.

does not run with optimum performance for petrol and kerosene fuels. Attachment of VCR is vital for this engine to improve the torque, power, BTE and BSFC. The proposed VCR mechanism can therefore be implemented in this engine for use with different fuels at corresponding optimum CR value.

\subsection{Investigations with large size engine}

Experiments are continued further with reference to the matrix in table 4, with implementation of in-house developed VCR mechanism in the large size KIRLOSKAR engine. Here, experiments are performed for $90 \%$ throttle opening, $28^{\circ}$ bTDC and $26^{\circ}$ bTDC ignition timings and for two CRs, viz. 9 and 9.79, with petrol and LPG as fuels, respectively. The test rig shown in figure 6 is employed for these experiments. Along with the measurements of torque, power and speed, combustion-related measurements are also undertaken. These measurements are then used to evaluate the BTE as well as BSFC and their variations are presented in figures 11 and 12 respectively. The nature of variation portrays the same trend for a given $\mathrm{CR}$ with change in speed as noticed for the small size HONDA engine. However, a noticeable fact here is that increment in $\mathrm{CR}$, at a given engine speed, decreases the BTE in case of petrol as fuel (figure 11a). Therefore, engine performance deteriorates with higher $\mathrm{CR}$ from its reference initial $\mathrm{CR}$ while working with petrol as fuel in this engine. However,

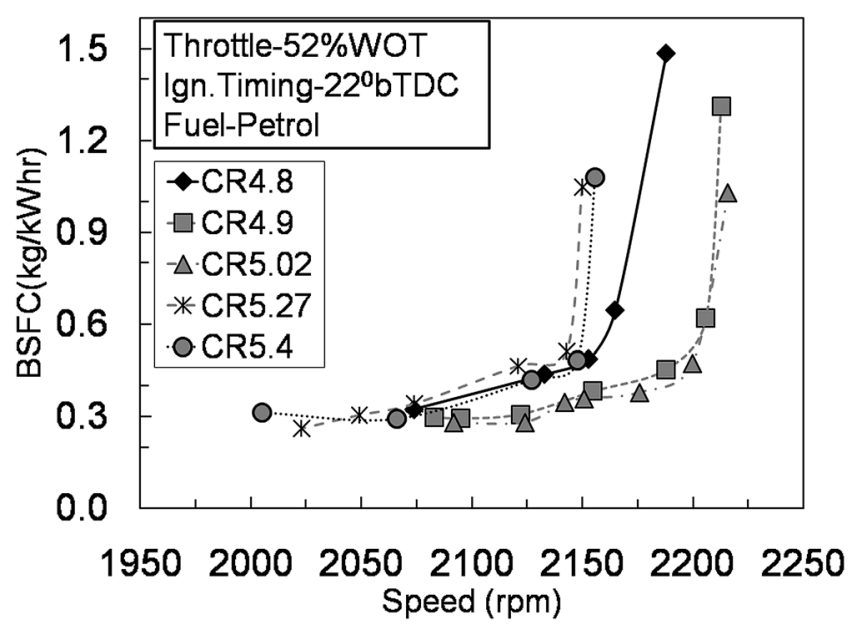

(a)

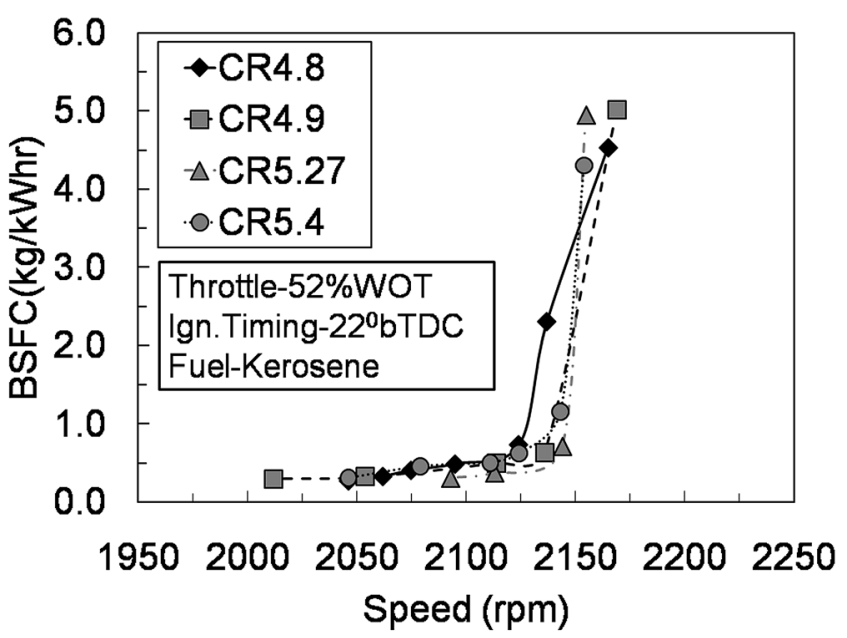

(b)

Figure 10. Variation of BSFC with modified head and VCR mechanism for (a) petrol and (b) kerosene. 


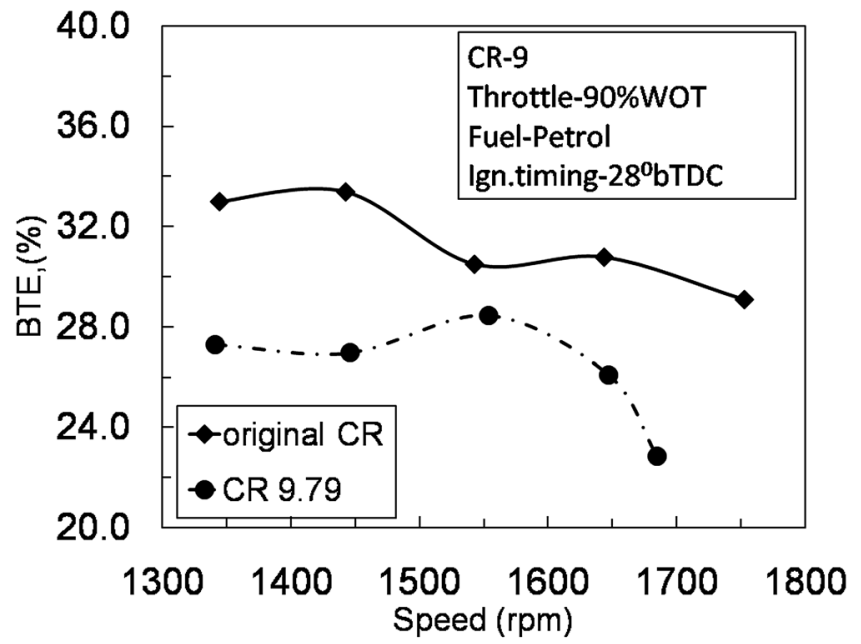

(a)

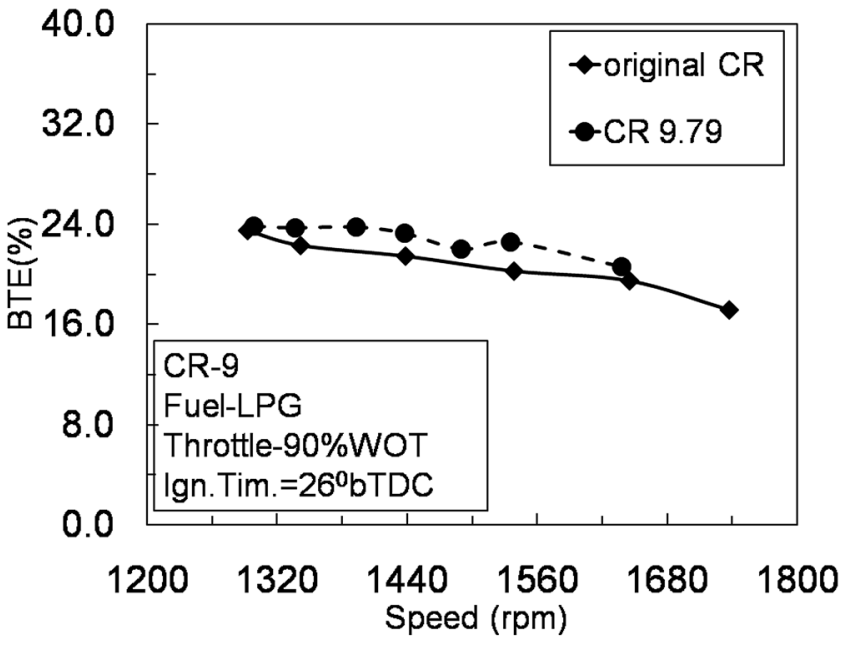

(b)

Figure 11. Variation of BTE of large size engine for (a) petrol and (b) LPG fuels.

there is a certain increment in BTE in case of LPG for increment in $\mathrm{CR}$ (figure 11b). Thus the engine performs better with LPG fuel at CR 9.79, where there is 6\% increase in BTE over its base value at CR 9. These observations for petrol and LPG are in line with the facts noticed in BSFC variation (figure 12). There is increment in BSFC if petrol is the engine fuel for increased CR. However, BSFC at CR 9.79 is $6.4 \%$ less if LPG is the engine fuel.

Cylinder pressure and combustion-related measurements are then analysed for the engine to understand the performance with both the fuels and CRs. Direct measurement of cylinder pressure for each degree of $\mathrm{CA}$ is as shown in figure 13 for petrol fuel. Peak pressure at CR 9 is 28 bar, which shows decrement by $32 \%$ at CR 9.79. Along with this, CA corresponding to peak pressure can be seen to be higher at higher CR, which is a sign of delayed combustion [33]. On the other side, when LPG fuel is tested in the same engine for CR 9 and 9.79, it is noticed that the cylinder pressure (figure 13) is 32.9 bar at CR 9.79 as compared with $28.1 \mathrm{bar}$ at original CR 9. Differential variation of engine performance with $\mathrm{CR}$ can be understood better from the combustion analysis. Net heat release rate (NHRR) is considered first to get the insight of combustion phenomenon. As shown in figure 14, NHRR shows peak net heat release to be $16.6 \mathrm{~J} /{ }^{\circ} \mathrm{CA}$ at $\mathrm{CA} 354^{\circ} \mathrm{bTDC}$ when the engine is operated at original CR 9 using petrol fuel. With rise in CR using the present VCR mechanism, NHRR shows increment in magnitude by $22 \%$ at CR 9.79 . However, this rise in NHRR cannot be converted to work for the reason of delayed combustion, where the maximum part of

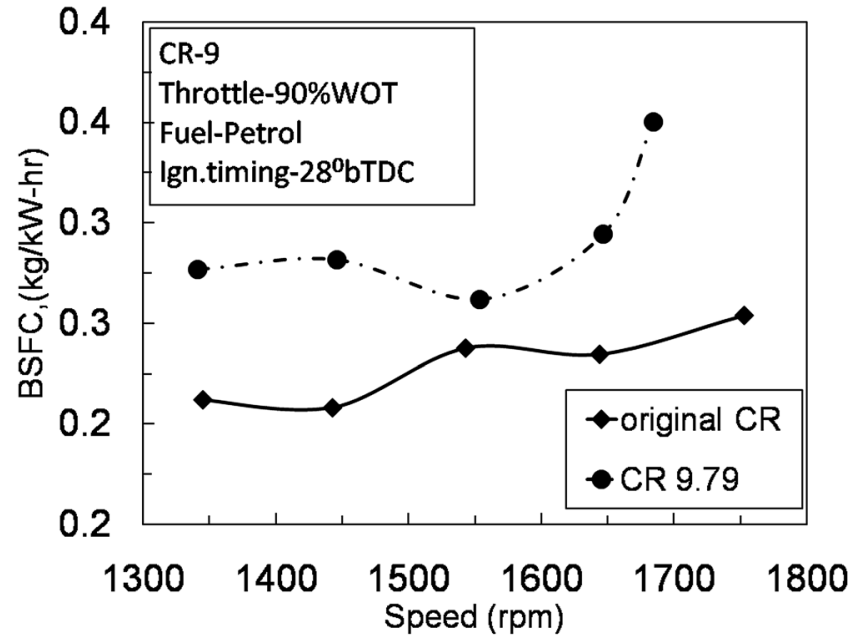

(a)

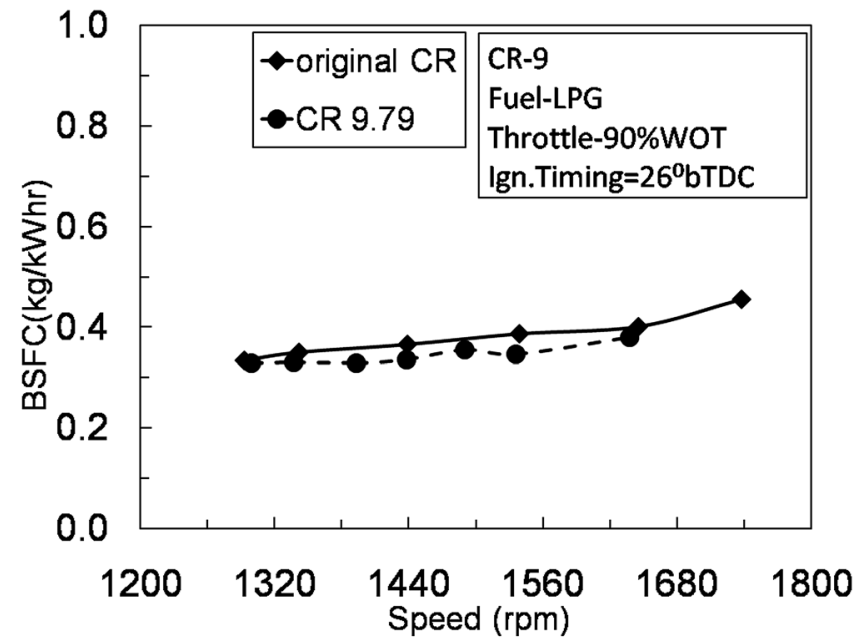

(b)

Figure 12. Variation of BSFC of large size engine for (a) petrol and (b) LPG fuels. 


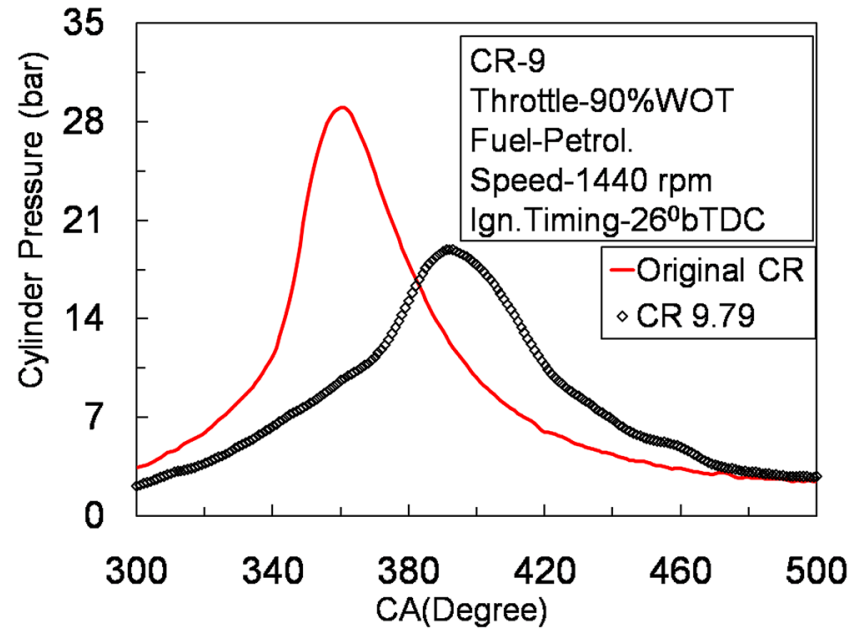

(a)

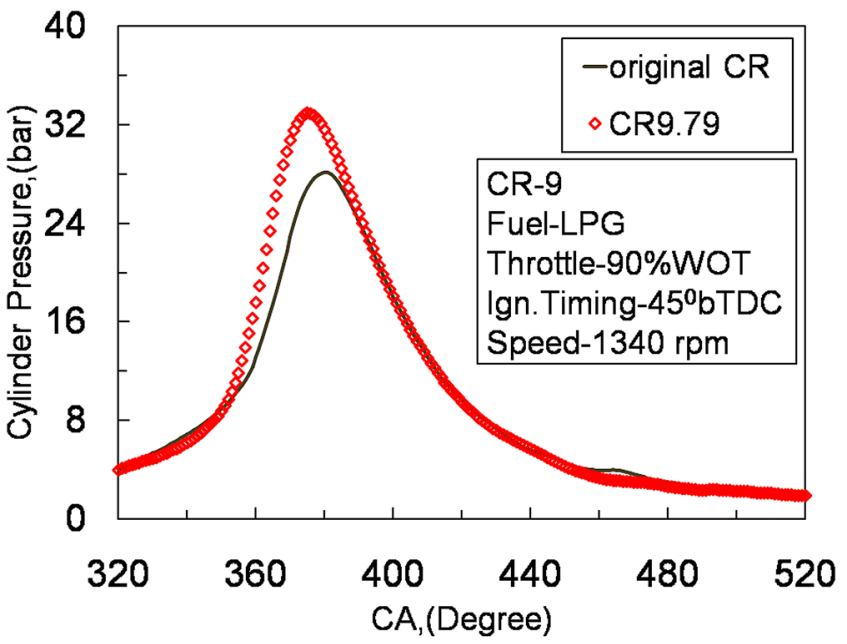

(b)

Figure 13. Variation of engine combustion parameters with modified head and VCR mechanism for petrol and LPG: (a) cylinder pressure for petrol and (b) cylinder pressure for LPG.

expansion stroke is wasted as heat release. Alternatively, LPG fuel combustion in the same engine (figure 14) shows NHRR of $23.4 \mathrm{~J} /{ }^{\circ} \mathrm{CA}$ at $\mathrm{CR} 9$ and CA $373^{\circ}$. When the CR is increased by the novel mechanism, the NHRR is found to be $30.4 \mathrm{~J} /{ }^{\circ} \mathrm{CA}$ at $366^{\circ} \mathrm{bTDC}$ for $\mathrm{CR} 9.79$. It shows that with LPG fuel the performance of the engine can be improved with setting of CR at 9.79. This may be due to the faster and complete combustion with higher flame travel. It can be verified more precisely using the term percent mass fraction burnt (MFB). Variation of percent MFB for petrol combustion with CA is shown in figure 15 .

At $360^{\circ} \mathrm{CA}$, the percent MFB for petrol fuel at CR 9 is $90 \%$ whereas for CR 9.79 it is $80 \%$. This shows clearly that flame speed achieves its maximum value and flame propagation takes place faster for original CR. Thus, the CR increased by VCR mechanism leads to delay in combustion after ignition. Therefore, the flame speed is low, which ultimately reduces the percent MFB at CR 9.79 for petrol fuel. However, in case of LPG fuel (figure 15), the percent MFB is $10.6 \%$ for original CR 9 at TDC, which increases to $28.4 \%$ for CR 9.79 at TDC. Thus, there is improved performance of the engine with LPG fuel. Use of percent MFB can be further extended for calculation of combustion duration, which is the time required for the charge to burn from the point of $10 \%$ MFB after spark initiation to the point of approximately $90 \%$ MFB. The combustion duration for CR 9 is $19^{\circ} \mathrm{CA}$ and at $\mathrm{CR} 9.79$ it is $20^{\circ} \mathrm{CA}$ while working with petrol. Therefore, it is evident that the

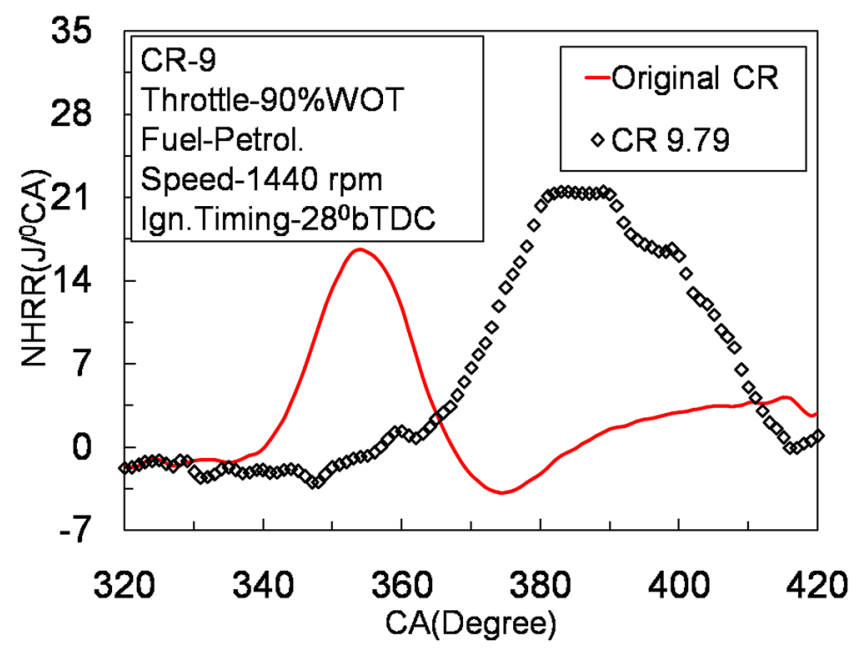

(a)

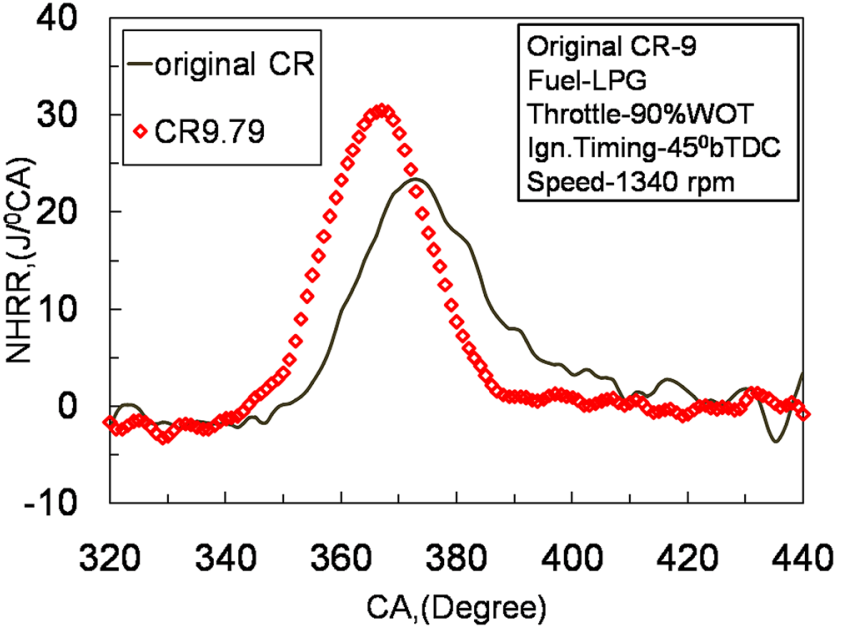

(b)

Figure 14. Variation of engine combustion parameters with modified head and VCR mechanism for petrol and LPG: (a) net heat release rate for petrol and (b) net heat release rate for LPG. 


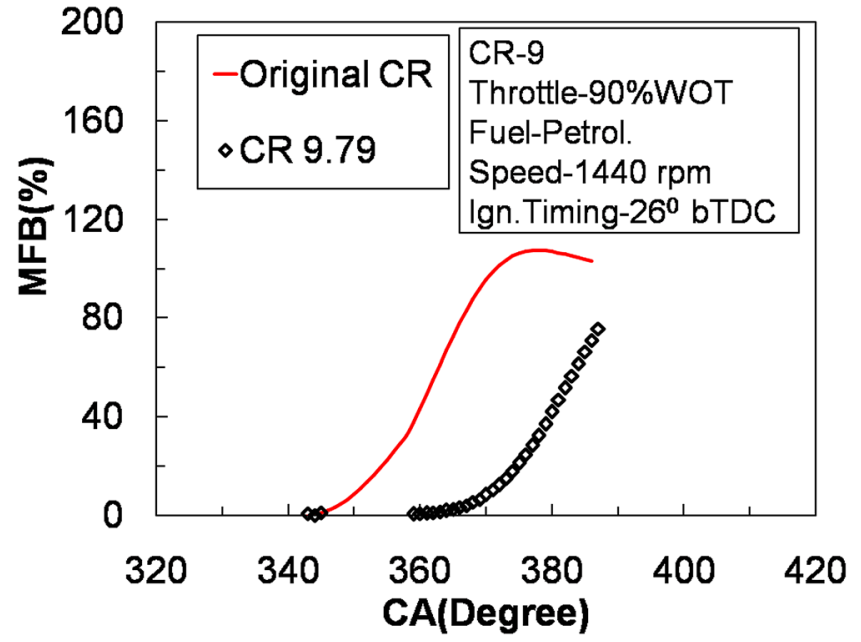

(a)

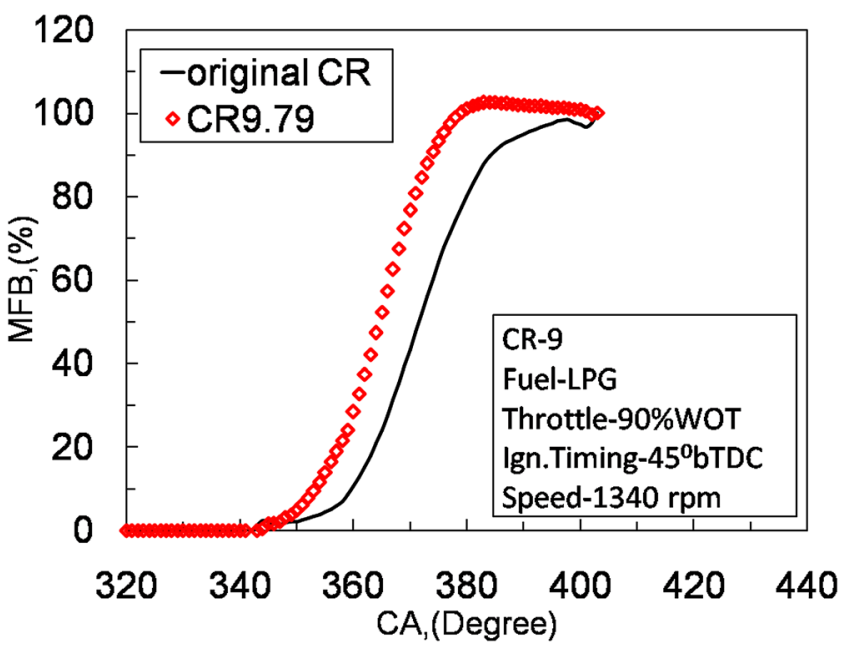

(b)

Figure 15. Variation of engine combustion parameters with modified head and VCR mechanism for petrol and LPG: (a) percent MFB for petrol and (b) percent MFB for LPG.

combustion duration is increased with increase in CR in case of petrol as fuel, while combustion duration of LPG is at $19^{\circ} \mathrm{CA}$ for $\mathrm{CR} 9$ and $17^{\circ} \mathrm{CA}$ at CR 9.79. Thus, the combustion duration for CR 9.79 is lower than that for CR 9. Therefore, peak cylinder pressure, NHHR, MFB and combustion duration clearly suggest that unlike petrol fuel, increase in $\mathrm{CR}$ leads to lower combustion duration, higher MFB, higher flame speed and higher peak cylinder pressure for LPG fuel. Hence, implementation of VCR mechanism is essential to improve the engine performance for alternative SI engine fuel. Moreover, increment in CR is not desirable if this engine is operated with petrol as fuel.

\subsection{Experimental uncertainty}

Uncertainty in present measurements has been obtained using the methodology reported in the literature [34-36]. It should be noted here that the uncertainties in the presently discussed parameter for HONDA engine are engine speed $( \pm 0.5 \%)$, brake load $( \pm 3 \%)$, mass flow rate of liquid fuel $( \pm 1 \%)$, mass flow rate of air $( \pm 1 \%)$, heating values of petrol and kerosene $( \pm 1 \%)$. Similar terms for the output parameters have been evaluated for KIRLOSKAR engine, i.e., brake power $( \pm 1.3 \%)$, BSFC $( \pm 1.3 \%)$, BTE $( \pm 1.6 \%)$, NHRR $( \pm 1.6 \%)$, engine speed $( \pm 0.5 \%)$, brake load $( \pm 0.5 \%)$ and cylinder pressure $( \pm 1.6 \%)$.

\section{Conclusions}

A novel variable compression mechanism has been implemented in two SI engines of different capacities. This mechanism is found to be appropriate and a viable alternative among the present available ones mainly due to possibility of changing $\mathrm{CR}$ in the running condition of the engine. Such a useful mechanism has been implemented in single-cylinder SI engines of different sizes. Small size HONDA engine of base CR 4.8 is initially considered for testing with the present VCR mechanism for two fuels (petrol and kerosene) where torque and power are measured in a specially designed experimental set-up. Optimum CR has been noted to be 5.02 for petrol and 5.27 for kerosene. Experiments with a larger size KIRLOSKAR engine of base CR 9 are then performed for torque, power, cylinder pressure, NHRR and MFB. Enhancement in engine performance has been noticed at CR 9.79 for LPG fuel while performance of petrol fuel is found to be better at base CR only. Faster combustion process and higher heat release rate are noted to improve the combustion characteristics of engine while operated with LPG at higher CR. However, delayed combustion is found to be responsible for lower performance at higher CR with petrol fuel. During present investigations, it has been revealed that the commercial engines with fixed CR have limitations in delivering higher performance for any fuel. Alternatives, like the present VCR mechanism, help the engine to operate with better performance not only for the default fuel but also for the substitutes. Thus, possibility of performance enhancement of the engine for a fuel by altering working CR and also accommodation of different fuels in the same engine have been demonstrated from current investigations.

\section{Acknowledgements}

Authors would like to thank the Department of Science and Technology, Government of India, for the financial support for facility development to carry out the present research. 


\section{List of symbols}

$b \quad$ width of piston ring

$B P \quad$ brake power (W)

$B S F C$ brake-specific fuel consumption $(\mathrm{kg} / \mathrm{kW}-\mathrm{h})$

BTE brake thermal Efficiency (\%)

CR compression ratio

$d_{p} \quad$ diameter of secondary piston ( $\left.\mathrm{mm}\right)$

$d_{\text {spark }} \quad$ diameter of spark plug $(\mathrm{mm})$

$E \quad$ modulus of elasticity of material $\left(\mathrm{N} / \mathrm{mm}^{2}\right)$

$F \quad$ force on piston due to combustion of fuel air $(\mathrm{N})$

$F_{a} \quad$ axial load (N)

$F_{r} \quad$ radial load $(\mathrm{N})$

$l^{\prime} \quad$ radius of neutral axis before installation $(\mathrm{mm})$

$l_{g} \quad$ circumferential gap of piston ring $(\mathrm{mm})$

$L H V \quad$ lower heating value of fuel $(\mathrm{kJ} / \mathrm{kg})$

$L_{h} \quad$ life of ball screw in millions of revolution

$m_{f} \quad$ mass of fuel consumed $(\mathrm{kg} / \mathrm{h})$

$n$ number of revolutions per cycle (for 4 strokes, $n=2$ )

$N \quad$ speed (rpm)

$P_{\max } \quad$ design pressure $\left(\mathrm{N} / \mathrm{m}^{2}\right)$

$P_{\text {rad }} \quad$ radial load on ring $(\mathrm{N})$

$r \quad$ radius of rope wire $(\mathrm{m})$

$r^{\prime} \quad$ radius of neutral axis after installation of ring (mm)

$R \quad$ radius of rope drum (m)

$S \quad$ spring load (N)

$t_{r} \quad$ radial thickness of piston ring (mm)

$t_{w} \quad$ thickness of secondary cylinder (mm)

$V_{c} \quad$ clearance volume $\left(\mathrm{cm}^{3}\right)$

$V_{d} \quad$ swept volume $\left(\mathrm{cm}^{3}\right)$

$X \quad$ radial force factor

$Y \quad$ axial force factor

$W \quad$ brake load $(\mathrm{N})$

$\sigma_{\text {allow }}$ maximum allowable stress $\left(\mathrm{N} / \mathrm{mm}^{2}\right)$

\section{Subscript}

act original

aux secondary

\section{References}

[1] Matson T 1924 Compensating connecting rod for internal combustion engines. US Patent 1506540

[2] Kratzer H J 1942 Variable compression ratio internal combustion engines. US Patent 2399276

[3] Mansfield W P 1956 Piston means for varying the clearance volume of an internal combustion engine. US Patent 2742027

[4] Clarke J R and Tabaczynski R J 2000 Internal combustion engine with adjustable compression ratio and knock control. US Patent 6135086

[5] Styron J P 2000 Variable compression ratio connecting rod for internal combustion engine. US Patent 7028647B2

[6] Moteki K, Fujimoto H and Aoyama S 2001 Variable compression ratio mechanism of reciprocating internal combustion engine. US Patent 6505582B2
[7] Brevick J 2000 Design and development of a pressure reactive piston $(P R P)$ to achieve variable compression ratio. Department of Energy Contract FC02-99EE50576, Final Technical Report 44-49

[8] Caris D F and Nelson E E 1959 A new look at high compression engines. SAE Trans. 67: 112-124

[9] Abdel V and Osman 1997 Experimental investigation of varying the compression ratio of SI engine under different ethanol-gasoline fuel blends. Int. J. Energy Res. 21: $31-40$

[10] Ozcan V and Jehad A A Y 2008 Performance and emission characteristics of LPG powered four stroke SI engine under variable stroke length and compression ratio. Energy Conserv. Manag. 49: 1193-1201

[11] Yuh M and Tohru G 2008 The effect of higher compression ratio in two-stroke engines. SAE 931512: 355-362

[12] Heywood J B 1988 Internal combustion engine fundamentals, International Edition. New York: McGraw Hill

[13] Baghdadi M S 2004 Effect of compression ratio, equivalence ratio and engine speed on the performance and emission characteristics of SI engine using hydrogen as a fuel. Renew. Energy 29: 2245-2260

[14] Aina T, Folayan C O and Pam G Y 2012 Influence of compression ratio on the performance characteristics of SI engine. Adv. Appl. Sci. Res. 3(4): 1915-1922

[15] Hanipah M R, Michelson R and Roskilly A P 2014 Recent commercial free-piston engine developments for automotive applications. Appl. Therm. Eng. 75: 493-503

[16] Boretti A 2013 Conversion of a heavy duty truck diesel engine with an innovative power turbine connected to the crankshaft through a continuously variable transmission to operate compression ignition dual fuel diesel-LPG. Fuel Process. Technol. 113: 97-108

[17] Hosey R J and Powell J D 1979 Closed loop, knock adaptive spark timing control based on cylinder pressure. J. Dyn. Syst. Meas. Control 101: 64-69

[18] Martyn R 2002 Benefits and challenges in variable compression ratio (VCR). SAE Technical Paper 03-227

[19] Sridhar G, Paul P J and Mukunda H S 2001 Biomass derived producer gas as a reciprocating engine fuel-an experimental analysis. Biomass Bioenergy 21: 52-72

[20] Yang J, Huang Q, Peng Z and Yu Y 2011 Simulation of piston-ring dynamics of a marine diesel engine. In: Proceedings of ICTIS 2011, pp. 2525-2536

[21] Budynas R G and Nisbett J K 2011 Shigley's Mechanical Engineering Design. New York: Mc-Graw Hill

[22] Bhandari V B 2010 Design of machine elements, 4th ed. New Delhi: Tata-McGraw Hill Education Pvt. Ltd.

[23] Mujumdar V V 2013 Ball screw catalogue. Pune: Institute of Applied Research

[24] Chaudhari A, Kulkarni V and Sahoo N 2014 Simulation models for spark ignition engine: a comparative performance study. Energy Procedia 54: 330-341

[25] Indian Standard 1980 Methods of tests for internal combustion engines-declaration of power, efficiency, fuel consumption and lubricating oil consumption. IS: 10000 (Part IV) Edition 1.1

[26] Chaudhari A, Kulkarni V and Sahoo N 2015 Effect of variable compression ratio and intake charge dilution on fuel efficiency and emission for a spark ignition engine. SAE Technical Paper. https://doi.org/10.4271/2015-01-0772 
[27] Debnath B, Saha U and Sahoo N 2014 Theoretical route toward the estimation of second law potential of an emulsified palm biodiesel run diesel engine. ASCE J. Energy Eng. https://doi.org/10.1061/(ASCE)EY.1943-7897.0000134

[28] Pulkrabek W 2003 Engineering fundamentals of internal combustion engine, 2nd ed. New Jersey: Prentice-Hall, Chapter 4, p. 148

[29] Sayin C, Kilicaslan I, Canakci M and Ozsezen N 2004 An experimental study of the effect of octane number higher than engine requirement on the engine performance and emissions. Appl. Therm. Eng. 25: 1315-1324

[30] Chandra R, Vijay V K, Subbarao P M V and Khura T K 2011 Performance evaluation of a constant speed IC engine on CNG, methane enriched biogas and biogas. Appl. Energy 88: 3969-3977
[31] Erkus B, Surmen A and Karamangil M I 2012 Comparative study of carburetion and injection fuel supply methods in an LPG fuelled SI engine. Fuel 107: 511-517

[32] Huang J and Crookes R J 1998 Spark ignition engine performance with simulated biogas - a comparison with gasoline and natural gas. J. Inst. Energy 71: 197-203

[33] Chiang C J and Stefanopoulou A G 2009 Sensitivity analysis of combustion timing of homogeneous charge compression ignition gasoline engines. J. Dyn. Syst. Meas. Control 131: 0145061-5

[34] Holman J P 1996 Experimental methods for engineers. New York: McGraw-Hill

[35] Kline S J and McClintock F A 1953 Describing uncertainties in single-sample experiments. Mech. Eng. 75: 3-12

[36] Moffat R J 1982 Contributions to the theory of single-sample uncertainty analysis. J. Fluids Eng. 104: 250-258 